\title{
Cold Storage and Temperature Management of Olive Fruit: The Impact on Fruit Physiology and Olive Oil Quality-A Review
}

\author{
Eddy Plasquy $^{1, * \mathbb{D}}$, José María García Martos ${ }^{1} \mathbb{D}$, María C. Florido ${ }^{2} \mathbb{D}$, Rafael Rubén Sola-Guirado ${ }^{3} \mathbb{D}$ \\ and Juan Francisco García Martín $4, *$ (D)
}

1 Department of Biochemistry and Molecular Biology of Plant Products, Instituto de la Grasa Spanish National Research Council, 41013 Seville, Spain; jmgarcia@cica.es

2 Department of Crystallography, Mineralogy and Agricultural Chemistry, Escuela Técnica Superior de Ingeniería Agronómica, Universidad de Sevilla, 41013 Seville, Spain; florido@us.es

3 Department of Mechanics, University of Cordoba, 14014 Cordoba, Spain; ir2sogur@uco.es

4 Departamento de Ingeniería Química, Universidad de Sevilla, 41012 Seville, Spain

* Correspondence: eddy.plasquy@telenet.be (E.P.); jfgarmar@us.es (J.F.G.M.)

Citation: Plasquy, E.; García Martos, J.M.; Florido, M.C.; Sola-Guirado, R.R.; García Martín, J.F. Cold Storage and Temperature Management of Olive Fruit: The Impact on Fruit Physiology and Olive Oil Quality-A Review. Processes 2021, 9, 1543. https://doi.org/10.3390/pr9091543

Academic Editor: Elwira Sieniawska

Received: 4 August 2021

Accepted: 27 August 2021

Published: 30 August 2021

Publisher's Note: MDPI stays neutral with regard to jurisdictional claims in published maps and institutional affiliations.

Copyright: (c) 2021 by the authors. Licensee MDPI, Basel, Switzerland. This article is an open access article distributed under the terms and conditions of the Creative Commons Attribution (CC BY) license (https:// creativecommons.org/licenses/by/ $4.0 /)$.

\begin{abstract}
Cold storage of olive fruit has been the subject of study for over more than 50 years. From the 1990s on, an increasing amount of knowledge is build-up about the impact of the conservation on the physiological response of the fruit as well as on the quality of the extracted oil therefrom. This review offers a comprehensive synopsis of this research, discusses the most important influential factors and summarizes the results on the influence of the studied parameters on both the fruit and the oil. Currently, changing climatic conditions, new harvesting techniques and a more demanding consumer market are triggering the need to broaden this strict focus on conservation. A more dynamic view on the effects of temperature from the moment the fruit is harvested up to the oil extraction process, reveals the necessity to manage this crucial influential factor more diversely. An overview of how this management can take form is structured through a focus on the different phases of the postharvest processing and the widely different harvesting scales. Future prospects of research are presented based on the actual state of the art of cold storage research as well as on the necessities that come forward from a broader fruit temperature management perspective.
\end{abstract}

Keywords: olive fruit; heat transfer; physicochemical analysis; postharvest; thermal treatment; temperature management

\section{Introduction}

The International Olive Council (IOC) defines virgin olive oils as "the oils obtained from the fruit of the olive tree (Olea europaea L.) solely by mechanical or other physical means under conditions, particularly thermal conditions, that do not lead to alterations in the oil, and which have not undergone any treatment other than washing, decantation, centrifugation and filtration." [1]. This definition underlines the importance and the strict relation between the fruit on the one side, and the obtained oil on the other. The quality of the latter depends to a large extent on the quality of the former. At the same time, the definition specifies the need to restrict to a minimum the treatments that can be applied before and during the extraction process and explicitly points to the importance of controlling the temperature during the processing.

Virgin olive oils are differentiated into Extra virgin olive oil (EVOO), virgin olive oil (VOO), ordinary virgin olive oil (OVOO) and lamp oil (LOO) [1]. EVOO is regarded as the olive oil with the highest quality. It has a free acidity, expressed as oleic acid, of no more than $0.8 \mathrm{~g}$ per $100 \mathrm{~g}(0.8 \%)$ besides other characteristics that correspond to those fixed for each category in the IOC standards. In the case of VOO, a maximum level of $2.0 \%$ free fatty acids (FFA) is tolerated and 3.5\% in the case of OVO. LOO's have a FFA of more than $3.3 \%$. Moreover, an evaluation by skilled tasters is mandatory and based on the absence 
(extra virgin) or the weak presence (virgin) of sensory defects and presence of three positive attributes: fruitiness, bitterness and pungency.

The applied harvesting method and the environmental conditions during the preprocessing storage of olive fruit are crucial factors in maintaining the quality of the fruit. For more than 30 years, both aspects have been studied intensively using the official physicochemical parameters and sensory evaluations that determine the quality of the oils and the impact of the applied treatments. The growing economic importance of premium olive oils further triggered fine-tuned studies in which more sophisticated variables and analyses were introduced to differentiate between olive oils that comply with the official EVOO standards and those that aspire to an even higher quality.

The storage of olive fruit has been investigated using different varieties, temperatures, conservation times and controlled atmospheres. The focus on the cold storage of olive fruit was initially driven by the need of finding a solution to a logistic problem, namely the managing of an increasing amount of fruit that needed to be processed as quickly as possible. Storing the fruit under optimum conditions was presented as an alternative that allows the use of the available equipment, avoiding significant investments. Later, various studies probed the possibility of modifying the specific characteristics of the olive oil, such as the bitterness and content of polyphenols, by cooling or heating the fruit just before or after being ground. More recently, attention is brought to the possibilities to fine-tune the temperature of the paste before entering the malaxer to optimize not only the malaxing process but also to correct too high or too low fruit temperatures. The latter necessity is becoming more and more relevant as the industry copes with fruit harvested at field temperatures that are too high for ideal extraction. At the same time, high field temperatures can induce fermentation processes during transport, especially when ventilation within the container is reduced.

The published studies in which the control of the temperature during the post-harvest and pre-processing stages came to play a crucial role thus not only increased during the last decade but also brought the possibilities of thermal modification more to the fore. Shifting from cold storage for several weeks to the necessity to control and correct the fruit or paste temperature during its processing, opened various lines of research in which the possibilities to dynamically modify the fruit temperature before their processing are a central focus. Simultaneously, new technologies are needed to incorporate this new challenge in the actual olive fruit harvesting and processing.

This review aims to present a comprehensive overview of the available literature concerning cold storage of olive fruit along with an outline of the advantages that dynamic control of the olive fruit temperature can offer and the unavoidable technological challenges such a shift inevitably implies. After a historical overview of the progress in this field, the most important independent variables that interfere in the cold storage of olive fruit are discussed as well as the actual state of the art concerning the chemical and physiological responses of olive fruit and the physicochemical characteristics of the oil extracted from cold-stored olives. In a third chapter, the focus is brought towards fruit temperature management as a novel framework to establish new technological challenges and opportunities.

\section{Cold Storage: An Historical Overview}

The first studies concerning the conservation of olive fruit were published in the 1960s. Researchers of the University of California envisioned the processing of table olives and studied the ripening and the storage of this fruit [2-4]. Their first aim was to define the lowest permissible temperature for storage while avoiding chilling injuries. Secondly, they explored the possibilities to apply a controlled atmosphere during storage. The experiments led to the conclusion that altering the oxygen and carbon dioxide concentrations around the fruit increased their susceptibility to chilling injury [3]. From 1965 on, the storage of olive fruit for oil extraction was tackled by Italian researchers working in the Instituto di Industrie Agrarie dell'Universitá di Perugia [5,6]. Aware of the deterioration of the 
olive fruit during storage they focused on two causes: the fruit constituents and the contamination by lipolytic microorganisms. The volatile and phenolic compounds of olive fruit processed immediately after harvest and stored at ambient temperature for 10 days were compared [7] and pointed to the loss of these components because of hydrolytic enzymatic mechanisms. The potential solutions varied from inactivation of fruit enzymes, dehydration, the use of inert gas atmospheres or ammonia; immersion into salt and acidic solutions, or treatment with fungicides or antibiotics [5-8]. However, and quite remarkably given the earlier published work [2-4], cold storage was not mentioned as a possible treatment. Meanwhile, at the University of California, the use of Controlled Atmospheres (CA) at various temperatures was further evaluated in order to maintain the quality of the fruit to extend the post-harvest life of 'Manzanillo' olives and underlined the potential to store olive fruit at $5{ }^{\circ} \mathrm{C}$ at $2 \% \mathrm{O}_{2}$ for up to about 12 weeks [9].

It is only from the 1990s that an increasing interest in the cold storage of olive fruit for oil extraction took form, resulting in a continuous increasing in published papers on the topic from the 90 s up to date (Figure 1).

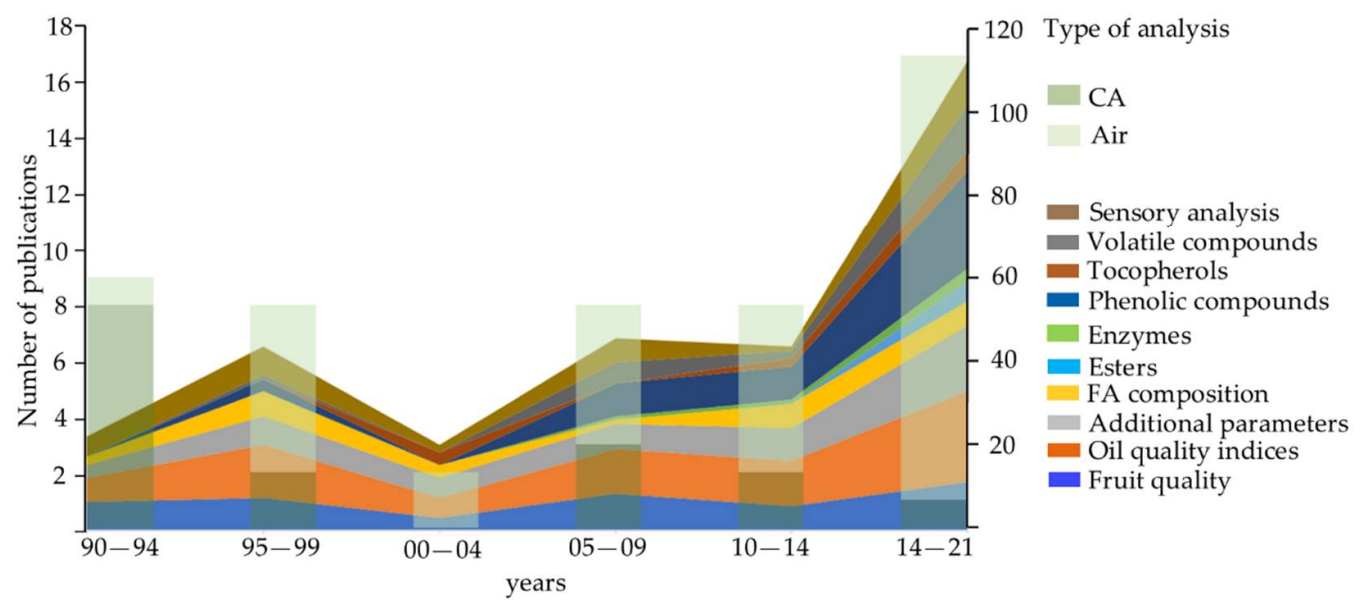

Figure 1. Number and type of works of analysis, under air and controlled atmosphere, published between 1990 and 2021.

The pivotal work of García and Streif [10], published in 1991, was followed with 8 more publications in the following 4 years, all belonging to a research group of the Instituto de la Grasa (CSIC) of Sevilla. Their focus included the effect of cold storage and CA during cold storage on the fruit as well on the extracted oil [11-14]. Fruit quality parameters and oil quality parameters (FFA, peroxides, K232 and K270, oxidative stability and sensory analysis) were measured, while more specific publications indicated shifts in polar compound concentrations [15], and changes in polyphenol content [16] when stored under different conditions. Whilst the advantages for cold storage became more and more clear at laboratory scale, attention was brought to the limitations of the used storage system especially when storage over more than 15 days in containers of $400 \mathrm{~kg}$ was envisioned $[17,18]$. In the following years, the experiments were scaled up to an industrial level and carried out on two different varieties, 'Blanqueta' and 'Villalonga' [19-22]. The results confirmed the advantages of cold storage and its potential for improving the processing. At the same time, it underlined the need for specific requirements, such as an adequate cooling installation to store the fruit that cannot be processed immediately, the capability to renew the air to avoid the accumulation of $\mathrm{CO}_{2}$, specific material, and machinery to handle the boxes and the supply of undamaged fruit. In the knowledge that each degree higher than $5{ }^{\circ} \mathrm{C}$ implies a significant reduction of energy costs, an experiment at a pilot-scale demonstrated that bringing the temperature from 5 to $8{ }^{\circ} \mathrm{C}$ would result in significant differences in fruit ripening and olive oil quality [20].

Meanwhile, Italian researchers built on the work of [7] and specified that to optimize the quality of the oil in relation to the level of ripeness and storage time, the latter could 
be stored up to a maximum of 6 days and even shorter when dealing with ripe olive [23]. A local variety from northeast Italy was used to focus on the effect of hypoxic and $\mathrm{CO}_{2}$ enriched atmospheres on olive ripening and oil quality [24]. As an alternative to cold storage, Koprivnjak et al. assessed an ancient conservation method from Croatia that consisted of keeping the olive fruit in seawater, a method that was previously mentioned by other authors $[5,6]$, only to conclude that although the basic physicochemical quality indicators did not change significantly, the sensory characteristics were affected dramatically [25].

The pioneering work of the group from the Instituto de la Grasa inspired researchers to design storage experiments with other varieties, modifying the temperature and the atmosphere. Significant intercultivar differences were observed between 'Sevilla' and 'Mission' cultivars on the hand, and 'Manzanillo' and 'Ascolano' on the other hand [26]. While the former could be stored up to 8 weeks at $5{ }^{\circ} \mathrm{C}$, the latter only lasted 4 weeks at the same temperature. A study on the 'Koroneiki' variety and designed a fine-tuned study in which the fruit was kept at 0,5 and $7.5^{\circ} \mathrm{C}$ while modifying the atmosphere at the same time [27]. They confirmed the earlier conclusions that cold storage at $7.5^{\circ} \mathrm{C}$ resulted in low quality and could largely be attributed to the development of fungus [20]. In line with the observations of Maxie, storage at $0{ }^{\circ} \mathrm{C}$ was neither recommended because of the risk of chilling injuries [3]. In the following decades, the potential to cold storage olive fruit was evaluated and confirmed by Californian [26,28], Australian [29]; Israelian [30], Italian [31-35], Spanish [36-46], Portuguese [47], Egyptian [48], Tunisian [49-54], Turkish [55], Iranian $[56,57]$ and Croatian [58] research centers, which used most of the time the local cultivars for their experiments.

Thus far, a total of 38 varieties has been the subject of an experiment related to the conservation and cold storage of olives (Figure 2).

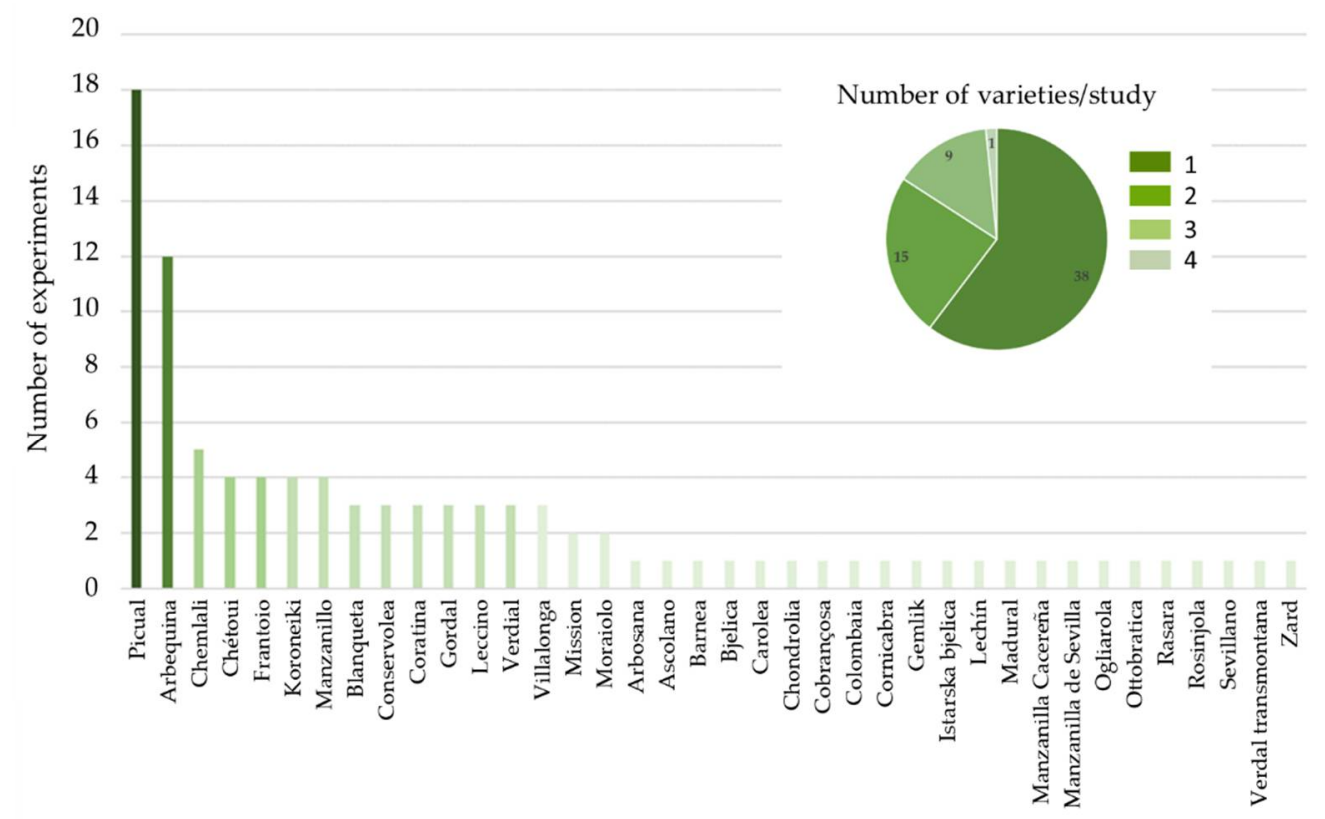

Studied varieties

Figure 2. Varieties used in cold storage experiments and the number of varieties per study.

The 'Picual' and 'Arbequina' stand out as the most studied varieties with 18 and 12 experiments, respectively, followed by 'Chemlali' (5), 'Chétoui' (4); 'Frantoio' (4), 'Koroneiki' (4) and 'Manzanillo' (4) cultivars. More than half of the varieties appeared only in one experiment (22). $60 \%$ of the experiments were realized with 1 cultivar, and 24 and $14 \%$ with, respectively, 2 and 3 cultivars. Only one study took 4 varieties into account (Figure 2).

The more than 60 published studies since the pivotal work of García et al. [10] are not evenly distributed over time but came in three waves (Figure 1). The first one was in the 1990s, during which the prospect for cold storage was evaluated for time spans 
up to 90 days and where the majority of the studies assessed the possibilities of CA. A second boost of studies arose from 2005 on, when CA became less prominent, and the mean maximum storage time was reduced to 30 days. Between 2015 and 2021 the number of publications doubled, while only marginal attention was given to $C A$, and the storage time was further reduced. From the second wave on, the type of analysis became not only more differentiated with an increasing focus on the phenolic and volatile compounds (Figure 1) but also more focused on the harvesting method. The last is in large part due to the progressive mechanization and the introduction of overhead mechanical harvesters in high-density orchards.

The broadening and the deepening of the research were mainly performed at the laboratory level, dealing with small quantities of fruit to keep the explanatory variables under strict control. Even though a few experiments were performed at a pilot-plant level and industrial level, cold storage has never been incorporated into the daily workings of an actual mill. The absence of thermodynamic studies to calculate the energy cost and economic studies to estimate the full size of a cold storage investment at an industrial level is in this respect striking but not surprising. At the time the alternative offered by cold storage was published, new extraction lines were already on the market, allowing mills to increase their milling capacity easily.

The prospect to modify the sensory characteristics of the extracted oil through thermal treatment of the olive fruit was suggested once it became clear that the amount of polyphenols in the oil was susceptible to temperature. However, experiments at laboratory as well as pilot plant scale, revealed that controlling the conditions to attain a desired level of bitterness was extremely difficult, if not impossible, given the influence of the fruit cultivar, their ripeness and their origin. At the same time, an inadequate application provoked a denaturalization of the fruit structure and undesirable emulsions during the malaxing [38,59-63].

Recently, the advantages of cold storage for small producers were brought to the attention. Keeping harvested olives at $5{ }^{\circ} \mathrm{C}$ for a short time, offered a solution to preserve the quality of the fruit until the necessary quantity for transport to the mill was reached. Combined with a gentle harvesting method, the refrigeration method made it possible to extract high-quality oil without disproportionate investments $[45,46]$. Cooling the fruit at the farm for a short term opens up new possibilities to revalorize the advantages of cold storage. Meanwhile, climatological changes and earlier harvests, especially of those varieties that are planted in high-density orchards, trigger new queries in which the management of the fruit temperature is coming to the fore as a key factor. The accumulated knowledge concerning cold storage did form a crucial element to address these new challenges.

\section{Explanatory Variables}

\subsection{Storage Temperature}

In $80 \%$ of the studies, the temperature for the cold storage experiments was kept at $4-6{ }^{\circ} \mathrm{C}$, following the recommendation given in earlier works to respect the $5{ }^{\circ} \mathrm{C}$ limit to avoid chilling injuries [3,4,9]. However, the control temperature varied significantly between 15 and $25^{\circ} \mathrm{C}$ in $75 \%$ of the cases, considered as ambient temperature (Figure 3 ).

This wider range is partly explained because several studies took the mean maximum day and night temperatures into account or registered the temperatures over longer storages times. A minority of studies used intermediate temperatures of $8{ }^{\circ} \mathrm{C}[17,18,20]$ and $10{ }^{\circ} \mathrm{C}[30,48]$.

Most of the published studies reported that the quality of the fruit and/or extracted oil were significantly lower when compared to a lower temperature over the same storage time. Yet, it was also suggested that 'Picual' and 'Koroneiki' cultivar can be stored at $10^{\circ} \mathrm{C}$ or even at room temperature for 9 days without much reduction in oil quality [30]. A few studies looked at the possibilities to keep the fruit at lower temperatures. Black 'Manzanillo' olives were stored at $0,2.2$ and $5^{\circ} \mathrm{C}$ for 6 weeks but, although no chilling injuries were observed, the oil extracted after 4 weeks of storage lost its quality as EVOO [28]. Mechanically and 
manually harvested olives of the 'Arbequina' variety, kept at $3{ }^{\circ} \mathrm{C}$ for 21 days neither presented chilling injuries [39]. 'Manzanilla de Sevilla' and the 'Manzanilla Cacereña' varieties were stored at $2{ }^{\circ} \mathrm{C}$ for 11 days in the best conditions without chilling damage [43].

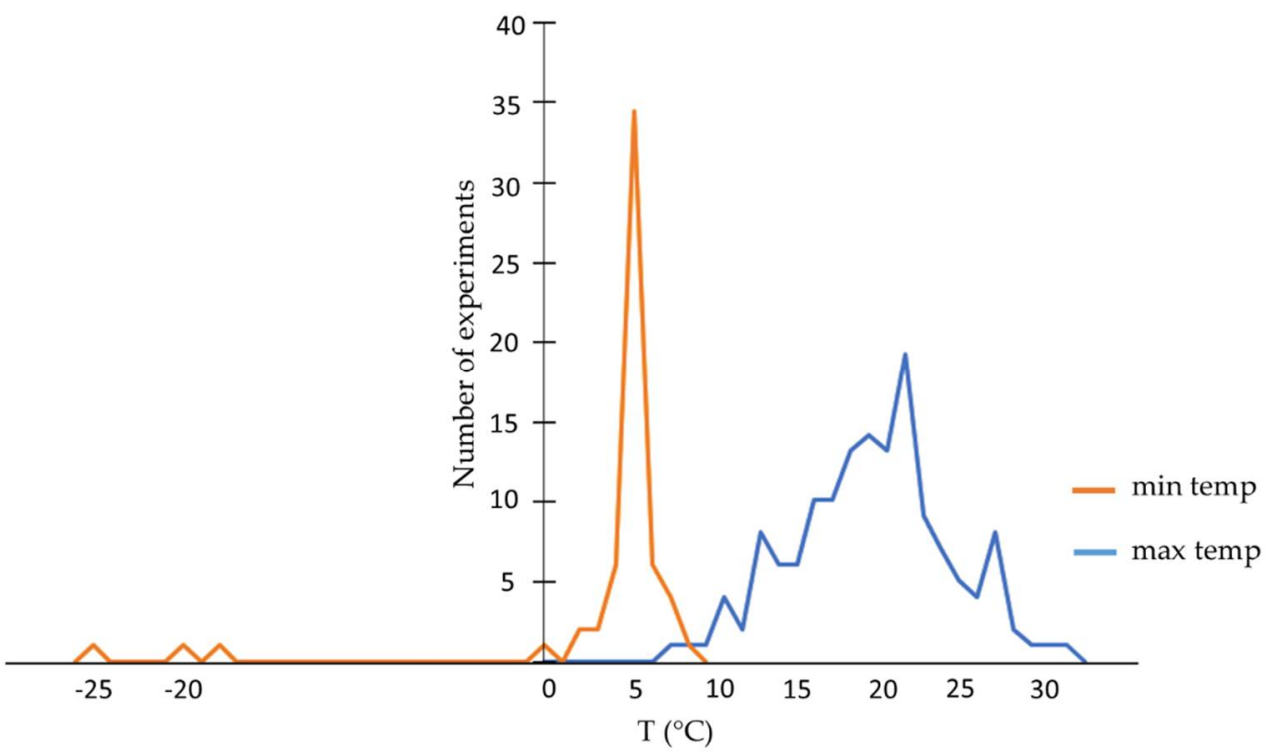

Figure 3. Temperatures use during several experiments of cold storage.

Storage at $0{ }^{\circ} \mathrm{C}$ was detrimental due to the destruction of the natural antioxidants present in the olive fruit, leading to a diminishing of the oxidation resistance [27]. Interestingly, oils obtained from 'Arbequina', 'Koroneiki' and 'Mission' cultivars that were kept at $-4{ }^{\circ} \mathrm{C}$ for up to 3 weeks, maintained the standard indices used for assessing virgin olive oil quality [64]; however, the amounts of FFA in the studied samples were not indicated in that study. After $24 \mathrm{~h}$ at $-18{ }^{\circ} \mathrm{C}$, a negative effect was found on the oxidative stability of $\mathrm{VOO}$ due to olive fruit freezing [65]. It is suggested that without thawing out the fruit before malaxation, the activity of oxidative enzymes is reduced. Olive freezing significantly modified the phenolic and volatile profiles of VOO from 'Picual' and 'Arbequina' cultivars [66]. Similar results were obtained after storing olive fruit at $-25^{\circ} \mathrm{C}$ for 6 months [67]. However, they underlined that the extracted oils met the standard commercial parameters for EVOO's while indicating that the sensorial defects may also be related to microbial activity. It was suggested that an olive sanitization treatment could possibly overcome this problem. The 'Koroneiki' cultivar was kept for up to 60 days at $-18,5$ and $20^{\circ} \mathrm{C}$, showing no negative effect of storage of olive samples at $-18{ }^{\circ} \mathrm{C}$ in the extracted oil based on the levels of acidity and peroxide values [57]. After 7 days stored at $4{ }^{\circ} \mathrm{C}$, the two Croatian cultivars, 'Istarska Bjelica' and 'Rosinjola', preserved the concentration of most phenolic compounds at levels that were comparable with fresh oil [58]. A decrease in sensory quality was observed after storage at room temperature and $-20^{\circ} \mathrm{C}$, leading to the conclusion that, under production conditions, refrigeration is the most suitable option when prolonged fruit storage is taken into consideration [58].

\subsection{Storage Time}

The storage time is a variable of major importance when the effects of cold storage on the physiology of the fruit as well as the quality of the extracted oils therefrom are examined (Figure 4). The effect of the storage time on the quality parameters, and especially on the FFA, is profoundly studied and confirmed for a wide range of varieties. 


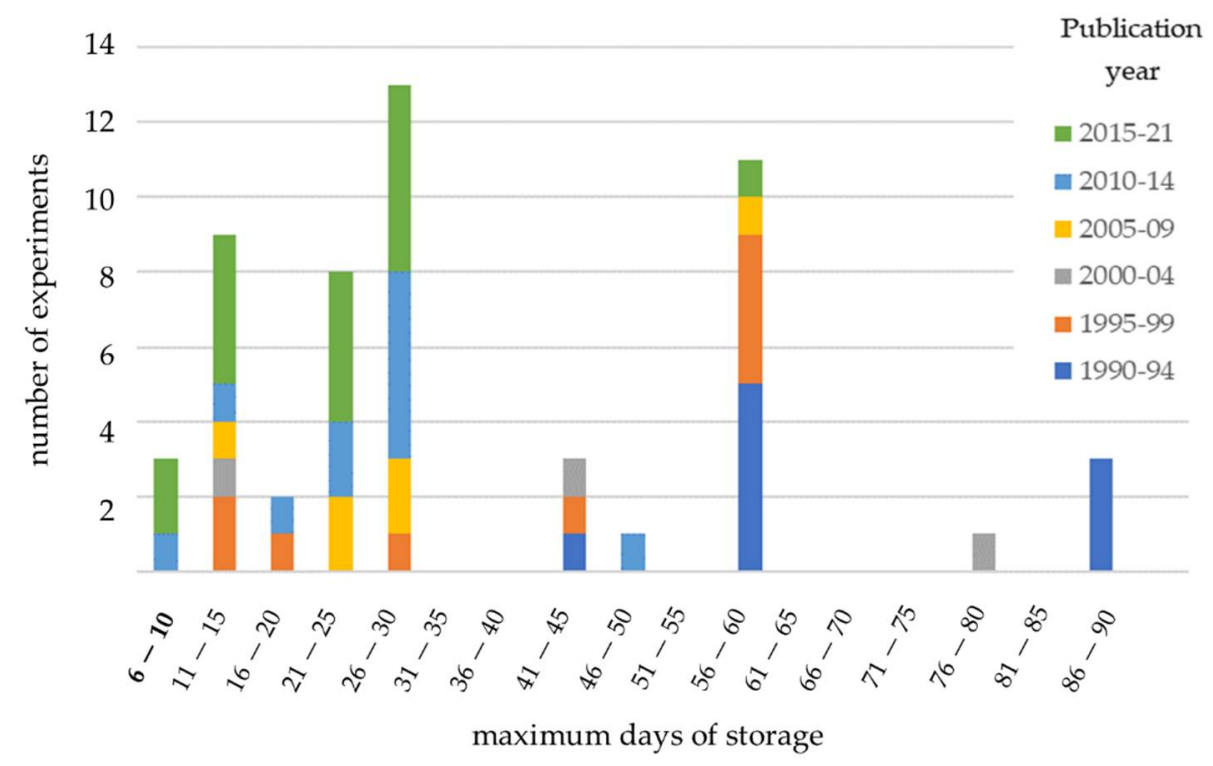

Figure 4. Maximum days of storage considered in the experiments between 1990 and 2021.

When in the 1990's the interest in cooling olive fruit took form, timespans up to 3 months were used to follow the official quality parameters of the olive oil $[10,17,27,68,69]$. Once it became clear that cold storage for more than one month resulted in problematic fruit quality and deficient oils, the maximum storage time was reduced and the observations were made within shorter intervals [29-31,45,46,49,51-53,70]. Monitoring the amount of polyphenolic and volatile compounds in the stored oils, triggered even more precise observations for only several weeks and between days [34,40-42,58]. More recently, the effect of short-term storage of less than one day is acquiring attention as a tool to modulate the aroma profile of the oil [71].

\subsection{Use of Controlled Atmosphere}

The prospect to control the atmosphere to enlarge the storage time while guaranteeing the quality of the fruit was extensively tested for table olives as well as for mill olives. Increasing the concentration of $\mathrm{CO}_{2}$ and/or the decrease of $\mathrm{O}_{2}$ allows, on the one hand, control of the development of fruit maturation and pathogenic proliferation and can delay the physiological changes due to chilling sensitive crops on the other [72]. On the other hand, these atmospheres can at the same time induce other physiological disorders and even aggravate chilling injuries for specific commodities.

The early experiments at Davis were designed to evaluate the effects of controlled atmosphere (CA) on olive fruit. Olives of the 'Manzanillo' and 'Mission' cultivars kept at $3.8^{\circ} \mathrm{C}\left(39^{\circ} \mathrm{F}\right)$ stored under low $\mathrm{O}_{2}$ and high $\mathrm{CO}_{2}$ concentrations were severely injured fruit due to chilling damage [2]. At the same time and based on color change, there was a clear indication of delaying ripening. 'Manzanillo' olives stored under different temperatures and levels of $5 \%$ of $\mathrm{CO}_{2}$ caused internal injuries, while storage at $2 \% \mathrm{O}_{2}$ retarded fruit softening and color changes [9]. Two Greek varieties for table olives, stored at $5{ }^{\circ} \mathrm{C}$, developed skin injuries after prolonged storage at high $\mathrm{CO}_{2}$ concentrations, with or without low $\mathrm{O}_{2}$. A significant difference was observed between the varieties, with 'Chondrolia' being highly sensitive to chilling injury and 'Conservolea' having the potential to be stored at $7 \cdot 5^{\circ} \mathrm{C}$ for up to 3 weeks under CA conditions $[68,69]$.

The possibility of applying CA to optimize the cold storage of mill olives was one of the main objectives of the research group of the Instituto de la Grasa of Seville (Figure 1). Their experiments all led to the conclusions that $\mathrm{CA}$ induced physiological disorders that facilitated fruit decay [10-15]. Oil extracted from these fruits resulted in poor quality levels, characterized by high acidy levels and sensorial defects. The results were confirmed by other authors, reporting the best results after 30 days under air at $5^{\circ} \mathrm{C}$ [27]; the lowest 
panel test scores were obtained for oils extracted from fruit kept during 11 days under low $\mathrm{O}_{2}$ and high $\mathrm{CO}_{2}$ concentrations [62]; several conventional and nonconventional analysis led to the conclusion that CA did not produce any remarkable advantage over storage at $5{ }^{\circ} \mathrm{C}[31,32]$. In the light of this evidence, the results obtained after the storage of Turkish 'Gemlik' olives under $\mathrm{CO}_{2}$ are quite surprising, as the treatment protected their physical properties up to 25 days, whilst the quality parameters were not affected, and no significant effect on the phenolic and fatty acid composition of the extracted oil were detected [55].

\subsection{Cultivar}

Even though the intervarietal comparison among different experiments is often complicated, if not impossible, due to other interfering factors such as different temperature, ripeness or storage conditions, sufficient studies do illustrate the significant effect of the genetic factor on the quality of the fruit and the oils extracted from olives that were coldstored. 'Villalonga' and 'Blanqueta' varieties showed significant differences between de levels of FFA of both cultivars when stored for more than 20 days at $5{ }^{\circ} \mathrm{C}$ [19]. 'Manzanillo' and 'Ascolano' could be stored up at $5{ }^{\circ} \mathrm{C}$ for 2 and 4 weeks, while 'Mission' and 'Sevillano' varieties could be kept in good fruit condition up to 6-8 weeks [26]. Comparing the Portuguese cultivars 'Cobrançosa', 'Madural' and 'Verdeal Transmontana', 'Verdeal Transmontana' deteriorated the most rapidly, while 'Cobrançosa' showed the best results in oil quality after cold storage op 14 days [47]. A significant difference in the bitterness intensity was observed among the 'Manzanilla', 'Picual' and 'Verdial' varieties when stored at $5{ }^{\circ} \mathrm{C}$ for 8 weeks [38]. Differences in the levels of decay as well as FFA were reported for three Italian cultivars ('Coratina', 'Olgiarola leccese' and 'Leccino') [32], while the effect of storage temperature and time on the oil quality of mechanically harvested olives from three varieties, 'Koreneiki', 'Picual' and Barnea' were compared [30]. Significant differences between the 'Manzanilla de Sevilla' and the 'Manzanilla Cacereña' were observed in a similar study [43]. Differences on both the fruit as well as oil characteristics of the cultivars studied were confirmed between the Italian varieties 'Carolea' and 'Ottobratica' [34] and the 'Arbequina', 'Picual' and 'Verdial' cultivars [45,46].

\subsection{Loading Unit}

The cooling process of fresh fruits and vegetables involves a complex interaction between the thermophysical properties of the commodity (heat generation due to respiration, specific heat and thermal conductivity), the kind of packaging and palletization, flow field parameters (airflow rate and cooling temperature) and the accessibility of the cooling air to the produce [73-77]. The storage of olives implies keeping the fruit in containers that reduces the physical and biological deterioration to a minimum. The capacity of these containers, or the quantity of fruit stored per loading unit, plays a critical role in the storage efficiency of the olives as the incidence of postharvest losses increased together with the container's capacity $[18,22]$. After 15 days at $5{ }^{\circ} \mathrm{C}$, the decay incidence approached $40 \%$ and at 30 days, and half of the container was rotten. The temperature in the inner zone of a container of $400 \mathrm{~kg}$ of 'Picual' never went below $25^{\circ} \mathrm{C}$. Olives stored in boxes with a capacity of $64 \mathrm{~kg}$, attained over the same period an incidence below $20 \%$ and showed an internal temperature of $6^{\circ} \mathrm{C}$. The incidence of the ones stored in boxes of 2 and $6 \mathrm{~kg}$, stayed below $10 \%$ after 45 days of storage. Olives kept in $400 \mathrm{~kg}$ containers gave oils with significantly higher acidity values than the ones from containers for 2, 6, $64 \mathrm{~kg}$ before 45 days of storage. Similarly, no appreciable differences were reported in the sensorial analysis. Based on these observations, the use of boxes with a capacity of $22 \mathrm{~kg}$ of fruit was recommended.

The effect of the layer thickness on the quality and the composition of the minor components was equally studied [40]. For up to 3 weeks, olive batches (ripening index of 4), were stored at 10 and $20^{\circ} \mathrm{C}$ in plastic boxes (capacity of $50 \mathrm{~kg}$ of olives) filled in different layers, from monolayer, $10 \mathrm{~cm}, 20 \mathrm{~cm}$ to $60 \mathrm{~cm}$ thickness. The VOO quality parameters were, besides being affected by the storage temperature and time, also significantly influences by 
the thickness of the layer. After 5 days of storage, the fruit stored with a $60 \mathrm{~cm}$ thickness reached the upper limit for the EVOO $(0.8 \%)$. The suggestion that olives can be stored for 15 days when placed in one layer at $10{ }^{\circ} \mathrm{C}$, does not offer a workable solution but instead, underline one of the bottlenecks in the cold storage of olive fruit namely the crucial importance of the loading unit.

The handling of many boxes leads to large, if not unsurmountable logistic problems once dealing with several tons. A precooling treatment to the harvested fruit before dumping them in a container for conservation was suggested and investigated [77]. In a first experiment, the evolution of the internal temperature of a container of $400 \mathrm{~kg}$ was assessed with and without a precooling treatment at $5^{\circ} \mathrm{C}$. In a second experiment, the effects of a short cooling treatment at $-18{ }^{\circ} \mathrm{C}$ to attain rapidly the desired $5^{\circ} \mathrm{C}$ was tested. In the container with fruit at a field temperature of $18^{\circ} \mathrm{C}$, the mean internal temperature descended towards $10{ }^{\circ} \mathrm{C}$ during the first week, followed by a more stabilized period with temperatures between 8.8 and $9^{\circ} \mathrm{C}$. The container with precooled fruit followed an inverse behavior. Starting at $5^{\circ} \mathrm{C}$ a slow rise was set in, amounting to $7.6^{\circ} \mathrm{C}$ on day 14 . The examined parameters of the extracted oils from both treatments showed levels that corresponded to the EVOO category, although the olives that underwent a precooling treatment in small boxes, did not experience a significant increase in the acidity level after 14 days of storage. A comparison with the published data [50] was complicated as neither the intactness nor the state of the ripening of the fruit was provided. Notwithstanding, the observed low acidity levels, suggest that additional factors must have exerted a detrimental effect on the fruit. While fruit at a field temperature of $18{ }^{\circ} \mathrm{C}$ is rather low as compared with the day temperatures at the start of the harvesting campaign when fruit temperatures above $25{ }^{\circ} \mathrm{C}$ are far from unusual.

Recently, the focus is brought to the short-term cold storage (16-18 h) in containers (perforated plastic bins), either filled with $250 \mathrm{~kg}$, or half-filled with $125 \mathrm{~kg}$, and perforated plastic boxes with $20 \mathrm{~kg}$ of fruit [77]. The surface-to-volume ratio (SVR) was 7, 10 and 16, respectively. Unfortunately, the used ambient temperature was only $13.5 \pm 1{ }^{\circ} \mathrm{C}$. Thus, the study evaluated the effect of a $5-6{ }^{\circ} \mathrm{C}$ fall in temperature. At ambient temperature, the core temperature of the boxes with an SVR of 10 and 16, attained equilibrium in $6 \mathrm{~h}$, while the temperature in bins with $250 \mathrm{~kg}$ (SVR 7) showed an increase which reached over $3{ }^{\circ} \mathrm{C}$ after $18 \mathrm{~h}$. Regarding the cooled containers, all three reached thermal equilibrium, although the cooling rate depended on the SVR. No significant differences were reported for the oil characteristics (quality parameters, phenolic compounds and VOCs). The concentration of $\mathrm{CO}_{2}$ was significantly higher in the refrigerated storage cell, while the $\mathrm{O}_{2}$ was significantly lower, showing that although the lower temperature reduced cellular respiration, large quantities of $\mathrm{CO}_{2}$ accumulated in olives stored in containers $(\cong 1 \%)$ while $\mathrm{O}_{2}$ decreased $(\cong 20 \%)$.

\subsection{Harvesting System}

In general, the published articles on the effects of the cold storage conditions on the quality of the olive fruit and the extracted oil used hand-picked olives for their experiments or gave no information on the harvesting method used. It is only with the rise of mechanization and specifically the introduction of straddle machines in super-intensive olive orchards, that the attention was brought to the degree of damage that the used harvesting method could provoke (Figure 5).

The effect of the used harvesting method on the fruit characteristics and the oil quality was brought to the fore [30]. The study reported quality parameters of the oil (FFA, peroxides, polyphenol content) after storage up to 23 days at $4,10{ }^{\circ} \mathrm{C}$ and ambient temperature. It was concluded that, at least for 'Picual', the modernization did not reduce the olive's capacity for storage when the results of [20] were taken as a reference. The potential damage during mechanical harvesting was minimized as well for the 'Koroneiki' variety, which kept the values suitable for EVOO up to 24 days when stored at $4^{\circ} \mathrm{C}$. A comparative study to evaluate the effect of the harvesting system and cold storage on 
'Arbequina' olive fruit and the chemical composition of the extracted oil, revealed that the used adapted wine grape harvester induced internal damage in the fruit that led to more rapid decay, softening and higher weight losses during storage [39,70]. Consequently, the chemical composition of the extracted oils was modified during storage, rendering inferior quality, a decline in oxidative stability and lower phenolic and volatile compounds. A similar study focused on the phenolic and volatile compounds and concluded that the cold storage of mechanically harvested olives was only effective for one of the studied cultivars, 'Manzanilla Cacereña' [43]. The damage caused by the grape straddle harvester provoked in the 'Manzanilla de Sevilla' cultivar a quick increase in decay and consequently in the acidity levels of the extracted oils, up to the level that the EVOO category was lost. In general, the levels of the phenolic and volatile compounds in the oils obtained from mechanically harvested olives were significantly lower than manually harvested. Few indepth studies have been performed on the effect of trunk shakers and hand-held machines. One study [35] used five different harvesting systems: (1) gentle manual harvesting; (2) manual harvesting using hand-held combs to detach the olives and nets placed under the tree; (3) using two hand-held pneumatic combs with telescopic handles to detach the olives, while collecting them on nets on the ground; (4) mechanical harvesting with a trunk shaker and a reversed umbrella to collect the olives; (5) a straddle machine. The results left no doubt that gentle hand-harvesting caused the least damage, whereas the trunk shaker and the straddle machine the greatest. Stored at ambient temperature $\left(18 \pm 2{ }^{\circ} \mathrm{C}\right)$, the observed fruit damage explained most of the worsening of oil quality across the studied harvesting systems and storage duration.

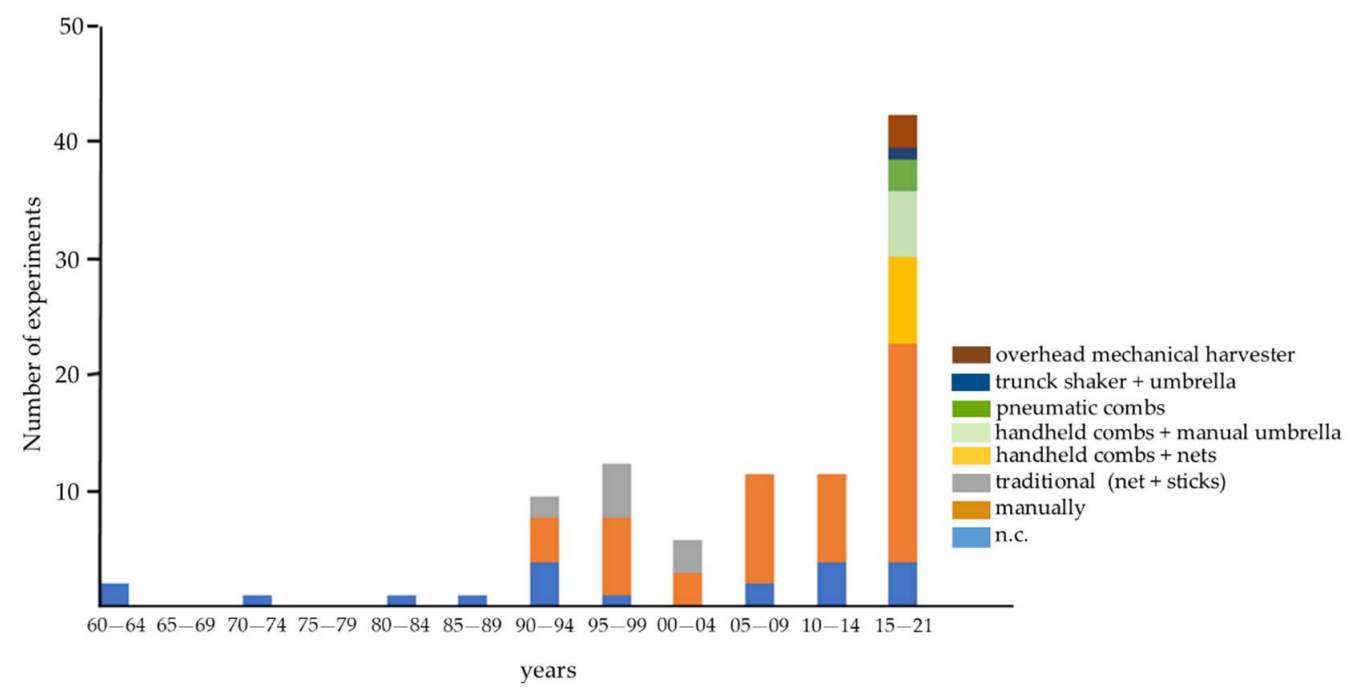

Figure 5. Harvesting methods used to harvest olive samples for the cold storage experiments.

The effects of a harvesting and conservation method, designed for small producers, on the fruit as well as the oil quality was presented by [45,46]. The studied harvest method consisted of hand-held pneumatic combs (branch shakers) together with a movable structure designed as an inverted umbrella that was placed around the tree, avoiding that the fallen fruit did not fall on the ground, but was recollected in perforated boxes, placed under the lowest part of the canvas [78]. After being harvested, the fruit was stored at the farm in a cold storage room at $5^{\circ} \mathrm{C}$ for up to 14 days. Three different varieties ('Arbequina', 'Picual' and 'Verdial') were tested. Fruit evaluation, physicochemical analysis and panel analysis revealed a significant effect of variety, as well as the harvesting and conservation method. Calculation of the magnitude of the strength and panel preference discerned the explanatory weight of each factor and emphasized the need to consider the days of storage when evaluation their importance. When the storage time falls within the range of a few days, the quality is best guaranteed by an optimized harvesting method. When longer storage is expected, high day temperatures are expected or when dealing with sensitive 
varieties, cold storage turned out to be unavoidable when a high-quality end-product is the goal.

\section{Effects on Fruit Physiology and Quality}

Harvested olive fruit is a living tissue that respires, consuming oxygen and liberating carbon dioxide [72]. The respiratory process produces the energy required for metabolic activities and fruit maturation. Cooling fruit decreases the effectiveness of the fruit respiration and by doing so the commercial life is extended for the produce stored. By slowing down the metabolic processes, the weight and nutritional value losses are reduced, while pathogenic deterioration of the olive fruit is delayed [22].

\subsection{Skin Color and Maturity Index}

The progress of the ripening can be registered through changes in skin color, using the CIELAB color space. Alternatively, the maturity index (MI) was calculated following a method that allowed an appreciation of the overall ripening stage of the olive fruit, based on both the skin and flesh color [79].

Each of the studies that used a colorimeter observed a significantly better color for the cold stored olives as compared with the ones kept at room temperature [10,14,20, $28,38,39,45,47,48,55,68,69]$. This effect became visible from the first week of storage and continued up to 30 days [10]. 'Picual' olive fruit kept at $5{ }^{\circ} \mathrm{C}$ maintained the same color during the first 14 days of storage independently of the atmosphere [14]. Similar results were obtained when measuring the color variance among 'Coratina', 'Manzanilla' and 'Picual' olives stored at $5{ }^{\circ} \mathrm{C}$ [48], and comparing the 'Arbequina', 'Picual' and 'Verdial' cultivars during 14 days at the same storage temperature [45]. A slight change in color after 7 days of storage of the 'Arbequina' variety was observed, independent of the harvesting method [39]. It was further reported that storage time and atmospheres had no significant effect on color $[28,55]$. In olive fruit stored at $5{ }^{\circ} \mathrm{C}$ under air, the red skin color was noticed after 45 days, while at $7.5^{\circ} \mathrm{C}$ it was observable after 30 days [69]. A significant change in color in the 'Picual' cultivar after one week of storage at $5{ }^{\circ} \mathrm{C}$ was reported, while this took 3 weeks for the 'Manzanilla' and up to 5 weeks for the 'Verdial' cultivar [38].

The same tendencies are described when the MI is used to quantify the ripening process and a significant delay of the maturation due to low storage temperatures is observed $[17,19,20]$. A reddish-brown skin color, corresponding to a number 3 , on the scale from 0 to 7 , was attained after 15 days when stored at ambient temperature, 30 days when stored at $8{ }^{\circ} \mathrm{C}$ and 45 days at $5{ }^{\circ} \mathrm{C}$. The obtained MI values in another study showed only a modest increase in the third and last week of storage at $4 \pm 2{ }^{\circ} \mathrm{C}$ [29]. The same range of variation was noted with respect to the studied cultivars [38]. Concerning the Croatian varieties, no significant rise in the MI was reported after 1 week of storage at $4{ }^{\circ} \mathrm{C}$ [58].

\subsection{Firmness}

The majority of the published studies define the firmness as the resistance to a deformation of the skin measured either with a shoremeter or densimeter, equipped with a 5- $[10,12,14,38,39]$ or 2-mm probe [55], expressed in Newton $/ \mathrm{cm}^{2}$, or with a momentum transfer generator (MTG), that reports the olive firmness as MTG units [28]. From the first studies on, it was demonstrated that the maintenance of flesh firmness depended on storage temperature [10]. At $5{ }^{\circ} \mathrm{C}$, the initial values are maintained, while at ambient temperature they fell to almost $50 \%$ after 30 days of storage. At $8{ }^{\circ} \mathrm{C}$, a moderate decrease was observed up to 60 days [17]. The fruit firmness of black-ripe olives declined by $24.4-45.9 \%$ in air and 34.2-38.0\% in $2 \mathrm{kPa} \mathrm{O}_{2}$ after 4 weeks of storage [28]. These observations were contrary to results on mature green olives which firmness was better when stored under 5 or $2 \mathrm{kPa} \mathrm{O}_{2}$ [14]. However, 'Gordal' olives stored under $1 \mathrm{kPa} \mathrm{O}$ did show a decrease in firmness [10]. The firmness of black-ripe olives at $20{ }^{\circ} \mathrm{C}$ decreased by $44 \%$ within the first 2 weeks, which was much lower than any of the other examined. Variations among cultivars were observed [26,38]. A clear difference was registered between the 'Mission' 
and 'Sevillano' varieties, which maintained their firmness up to 8 weeks, and the 'Acolano' and 'Manzanillo' cultivars, which, respectively, lost 9 and $29 \%$ of their firmness at 4 weeks and 16 and $53 \%$ at 8 weeks [26]. Significant differences occurred between 'Picual', showing a significant reduction of the firmness after 1 week, and the 'Manzanilla' and 'Verdial' varieties, only after 4 and 6 weeks, respectively [38]. Hand-harvested olives softened slower as compared to mechanic harvest. However, it was only after 10 days of storage at $5{ }^{\circ} \mathrm{C}$ that a significant difference was observed. A difference that was contributed to the internal partial breakage of the cellulose walls of the cells of the mesocarp during mechanical harvesting [39]. A similar observation was made in a recent research [45], in which the use of nets was the damaging factor.

\subsection{Humidity}

The amount of humidity lost during the storage is measured as the difference between fresh and dry mass and expressed as \% [12]. Water loss increased significantly in studies that stored the fruit for more than 60 days $[12,14]$. Higher temperature and lower relative humidity do provoke higher losses in fruit stored at ambient temperature, while an advanced stage of fungal decomposition induces leakage of cell fluids [12,14]. Kept at $5{ }^{\circ} \mathrm{C}$ and up to 60 days, no differences were observed among the fruit stored under different atmospheric concentrations. No significant differences in water content in black-ripe olive were observed after storage of 2 weeks at $20^{\circ} \mathrm{C}$ [26] and neither in the 'Gemlik' variety after 25 days of storage [55]. However, these results were not confirmed by other studies [48,57]. The former authors registered a significant decline in humidity after 1 week when stored at $20{ }^{\circ} \mathrm{C}$, while at 5 and $10{ }^{\circ} \mathrm{C}$ this parameter did not change [48]. Nevertheless, after 2 weeks the fruit stored at the lowest temperature kept significantly higher moisture when compared with the one at $10{ }^{\circ} \mathrm{C}$. The latte authors mentioned a significant decrease of water content after over 20 days for the fruit stored at $20^{\circ} \mathrm{C}$ or $5^{\circ} \mathrm{C}$ [57].

\subsection{Weight Loss}

Weight loss is one of the main postharvest changes in fruit and vegetables due to respiration and transpiration. It includes, beside the loss of water, also the loss of other substrates (sugars, organic acids ... ) that are consumed by the fruit metabolism during the storage. To quantify the weight loss of the olives, the fruit is weighed with a balance before and after each treatment and storage duration. The difference is expressed as percentage loss. Weight losses increase with time over storage $[26,27,39,45,48,68,69]$. The highest losses were observed at $7.5^{\circ} \mathrm{C}$ as compared to at $5{ }^{\circ} \mathrm{C}$ under air [27]. At a lower storage temperature and under controlled atmospheres, the weight loss decreased. Slight differences between the two studied varieties, 'Sevillano' and 'Manzanillo', were reported [26]. While the mass loss after 2 weeks increased in the former by $0.6 \%$, the latter attained $1.5 \%$ when stored at $5{ }^{\circ} \mathrm{C}$. At $20^{\circ} \mathrm{C}$ the mass loss attained levels between 2.3 and $3 \%$. Varietal variance was also observed among the 'Coratina', 'Manzanillo' and 'Picual' varieties with 16,12 and $11 \%$ weight loss, respectively, when stored at $20^{\circ} \mathrm{C}$. When stored at $10^{\circ} \mathrm{C}$, the weight loss was more than 3 folds those at $5^{\circ} \mathrm{C}$. Prolonging the storage period led to a significant increase in weight loss for all the cultivars [48]. Similar varietal differences between 'Chondrolia' and 'Conservolea' were reported, although the authors pointed out that this might be due to high chilling injury of the epidermis of 'Chondrolia' [69]. Notwithstanding, the study underlined that the olive mass loss increased with storage temperature and duration for both cultivars. This process was accelerated when stored under a controlled atmosphere. The influence of $\mathrm{CO}_{2}$ during the storage at $5^{\circ} \mathrm{C}$ is reported as a higher value of average weight at 5 and 15 days with CA, however, the differences became insignificant after 25 days [55]. Significantly higher weight losses were observed in the mechanically harvested 'Arbequina' samples [39]. The difference was attributed to the possible internal breakage that led to a lower juice content. The recent experiments of Plasquy et al. showed only an effect of the conservation temperature and the storage time on the weight loss for the three varieties studied ('Arbequina', 'Picual' and 'Verdial') [45]. 


\subsection{Oil Content and Oil Yield}

The oil content was determined either by Soxhlet extraction $[26,39,40,58]$ or the method described by Folch et al. [80] (cited in [48]). No significant changes depending on the fruit storage temperature were reported, indicating that accumulation of the oil did not continue during storage $[39,40,58]$. It was specified that although the oil content remained unchanged in four cultivars studied during storage at $5{ }^{\circ} \mathrm{C}$, when stored at $20^{\circ} \mathrm{C}$, it was lower than the initial values for the 'Manzanillo' and 'Ascolano' varieties [26]. On the other hand, a significant decrease of the oil content was observed with an increasing storage temperature and the progress of the storage period up to seven weeks [48].

To estimate the oil yield of the olive under different storage treatments, the decanted volume obtained through extraction with an Abencor system was used, considering the value of $0.915 \mathrm{~g} \mathrm{~mL}^{-1}$ as the value for oil density to obtain the yield as expressed as the percentage of fresh weight $[14,38-40,57,81,82]$. An alternative method [83] takes the mass ratio of the mechanically extracted oil and the centrifuged olive paste and multiplies the result by 100 [58]. One study carried out on a pilot plant scale obtained the data from the producer [29]. The extractability index (EI) was calculated based on the mean value of the percentages of oil physically extracted from the total oil content.

All the published studies reported higher oil yields from olive stored at ambient temperature $[11,38-40,57,58]$. During the first 2 weeks of storage at $5{ }^{\circ} \mathrm{C}$ a significant reduction of the yield for the 'Picual' and 'Verdial' cultivars was observed, followed by a gradual increase up to levels significantly higher than the initial ones [38]. The 'Manzanilla' variety, on the other hand, had a low oil yield from day 0 (4.6\% against $18.2 \%$ and $20.0 \%$ for the 'Picual' and 'Verdial' varieties, respectively) but did not show any significant change. This was related the higher values to the fact that the fruit could continue to ripen at room temperature, facilitating degradation of the walls of oil-bearing cells and consequently an improvement of the extraction process [38,39]. This hypothesis was supported by other authors [58] who also found the highest values of oil yield and EI in olives stored at room temperature. At the same time, it was underlined that the EI is highly dependent on the cultivar and fruit properties. An increase in oil yield in the first 2 weeks of cold storage was observed, followed by a decrease [29]. It is suggested that the increase is a consequence of cell-wall degradation due to low-temperature storage. After two weeks, most of the oil trapped in the cells was easily released. The decrease after 3 weeks was attributed to an advanced stage of hydrolysis.

\subsection{Incidence of Decay}

Fungal rot was determined visually when fungal mycelium was observed in randomly selected samples of 100 olives and expressed as a percentage of decay [12,14,17-20,26,39,43]. One study used an ordinal scale for 0 to 5 ( 0 : not rot, 1, few rotting olives without sporulation; $2,30 \%$ rotting but few sporulation; 3, 50\% rotting and sporulation; $4,75 \%$ rotting and sporulation; $5,100 \%$ rotting and sporulation) [27].

Low temperatures do reduce fungal growth. Olive fruit from the 4 studied varieties ('Ascolano', 'Manzanillo', 'Mission' and 'Sevillano') only showed little or no rot visible on the fruit after 5 weeks of storage at $5{ }^{\circ} \mathrm{C}$ [4]. However, after 10 weeks of storage, considerable numbers of decayed fruit were recorded in all varieties. Stored at $12{ }^{\circ} \mathrm{C}$, the decay of 'Picual' olives was more than $20 \%$ after only 7 days. At $5{ }^{\circ} \mathrm{C}, 45$ days of storage were needed to attain the same level. An intermediate behavior was observed when stored at $8{ }^{\circ} \mathrm{C}[17,18]$. The authors further observed that the entire batch of fruit, stored in air and ambient temperature, was affected at 30 days of storage. Similar results were obtained with the 'Villalonga' and 'Blanqueta' varieties [19]. Stored at $5{ }^{\circ} \mathrm{C}$, only about $20 \%$ were rotten after 60 days, while this level was already attained before 20 days at ambient temperature. Under ambient temperatures, 'Blanqueta' was significantly more resistant when compared to 'Villalonga', but when refrigerated, no difference was found. A more pronounced intercultivar variance was observed between 'Manzanillo' and 'Ascolano' with a high decay incidence (12 and 7\%, respectively, after 4 weeks, and 90 and $27 \%$ after 
6 weeks at $5{ }^{\circ} \mathrm{C}$ ) and the 'Sevillano' and 'Mission' olives, where the first had 13 and $11 \%$ decay after 6 and 8 weeks, respectively, and the second only $8 \%$ after 8 weeks. When kept at $20^{\circ} \mathrm{C}$, the 'Manzanillo' and 'Ascolano' olives showed 40 and $23 \%$ decay incidence after 2 weeks, the 'Sevillano' $6 \%$ and the 'Mission' cultivar no decay [26]. The fungal damage on 'Koroneiki' was manifest (score of 4) after 30 days of storage at $7.5^{\circ} \mathrm{C}$, independently whether CA was applied or not. At $0{ }^{\circ} \mathrm{C}$ in air and $5{ }^{\circ} \mathrm{C}$ under $2 \%$ of $\mathrm{O}_{2}$ and $5 \%$ of $\mathrm{CO}_{2}$, no rot (score 0 ) was observed after 30 days. At $5{ }^{\circ} \mathrm{C}$ in air, few rotting olives were present (score 1). At 60 days of storage the values for each treatment augmented 1 point [27]. The application of CA did not result in significant differences until 60 days of storage after which a higher degree of infection was observed. This shift was attributed to the lowered resistance to the molds, because of the combined effects for high $\mathrm{CO}_{2}$ and/or low $\mathrm{O}_{2}$ and low temperatures [14].

Fruit with physiological disorders or mechanical damage developed infection preferentially $[19,20]$. Mechanically harvested olives showed a significantly higher incidence of decay when compared to hand-picked olives, regardless of the storage temperature [39]. Independently the method of harvesting, the fruit stored at $3{ }^{\circ} \mathrm{C}$ showed a lower percentage of decay. Mechanically harvested 'Arbequina' olives attained almost $30 \%$ of decay after 4 days of storage at $18{ }^{\circ} \mathrm{C}$, a level that was not attained when stored during 10 days at $3{ }^{\circ} \mathrm{C}$. It was also remarkable that the harvesting system provoked mechanical damages that led to their rapid deterioration, even when the damage was not visually perceptible. A significantly higher decay incidence was reported between the fruit of the 'Manzanilla de Sevilla' and 'Manzanilla Cacereña' varieties in a hedgerow plantation, and hand-picked olives, although the difference was more pronounced in the first variety [43]. The authors referred to an earlier study in which they compared the damage caused by the used grape straddle harvester in the studied cultivars. The fact that a higher proportion of fruit with cuts was found in green 'Manzanilla de Sevilla' (18\% versus $2 \%$ ) may explain the intervarietal difference. Storage during 11 days at $2{ }^{\circ} \mathrm{C}$ was highly effective for controlling the fungal rot in the mechanically harvested 'Manzanilla de Cacereña', while the 'Manzanilla de Sevilla' attained an incidence of $30 \%$ under these conditions.

\subsection{Microbiological Profile}

To study the production of volatile phenols, related to the appearance of VOO sensory defects, the specific microbiological profile on the olive surface of fruit stored in plastic bags and open boxes at $5 \pm 3{ }^{\circ} \mathrm{C}$ by night and $8 \pm 3{ }^{\circ} \mathrm{C}$ by day up to 21 days was determined $[41,42]$. The viable-culturable cell number was determined on different substrates to evaluate the presence of fungi, lactic acid bacteria, enteric bacteria and Pseudomonas. The study revealed that only fungi were present at the initial time. Acetic bacteria attained levels above $104 \mathrm{cfu}$ (colony forming unit) per gram after six days, while the presence of enteric bacteria reached this level at day 5 of storage in a bag and day 15 in an open box. The lactic bacteria became only present after 9 days and the Pseudomonas only after 15 days when stored in a bag. One study [33] focused on the presence of two enzymes, responsible for the oxidation process of the phenolic compounds. The research considered both the phenoloxidase and the peroxidase from the spontaneous microbiota as possible oxidoreductases enzymes involved in the polyphenol decay in the oily fraction of the fruit during storage at $15^{\circ} \mathrm{C}$ and registered the total bacteria count, the total molds, and the total yeasts. The microbiological analysis showed a rapid increase of total bacteria and yeasts during the first 4 days of storage. Thereafter, they stabilized at 105 and $106 \mathrm{cfu} / \mathrm{g}$. The molds increased rapidly but never attained a level above $102 \mathrm{cfu} / \mathrm{g}$. The trials further showed that after 3 days of storage, only the total polyphenols presented in the oily fraction decreased rapidly. This was attributed to both the activity of the oxidoreductase's enzymes from the pulp and the microbiota on the carposphere and in the pulp of damaged fruit. 


\subsection{Respiration Rate}

Low temperature has a direct effect on the respiration rate. Keeping the fruit at $5{ }^{\circ} \mathrm{C}$ reduces the metabolism of the fruit cells. When comparing the respiration rate of olive fruit ('Gordal' cultivar) over $10 \mathrm{~h}$, a ten-fold higher $\mathrm{CO}_{2}$ production was registered when stored at $18{ }^{\circ} \mathrm{C}$ instead of $5{ }^{\circ} \mathrm{C}$ [10]. Similar results were observed with 3 Italian cultivars ('Coratina', 'Olgiarola' and 'Leccino') [32]. When kept under $2 \% \mathrm{O}_{2}$ and $5{ }^{\circ} \mathrm{C}$, the respiration rate was about three times lower than when stored in ambient air. In the same line, a significant effect on 'Manzanillo' olives stored at three temperatures between 5 and $10{ }^{\circ} \mathrm{C}$ of both the temperature and atmospheric composition was reported [28]. An increased respiration rate was described when the storage temperature rose, while black olives showed higher values than green at each temperature tested [68]. The values of the $\mathrm{CO}_{2}$ production of 'Arbequina' olives that were systematically could be ordered according to the cold storage temperature [70].

The respiratory quotient (RQ), or the ratio of $\mathrm{CO}_{2}$ produced to $\mathrm{O}_{2}$ consumed, is assumed to be equal to 1.0 if the metabolic substrates are carbohydrates. The overall values were calculated to be a little above 1 for the green and black 'Conservolea' cultivar when stored at temperatures between 0 and $20^{\circ} \mathrm{C}$ during the 24 days [68]. Similar values were obtained at harvest, but a pronounced decline was noticed parallel with the respiration rate for 2 days when stored at temperatures between 10 and $40{ }^{\circ} \mathrm{C}$ [81]. This decline was the most pronounced at $40^{\circ} \mathrm{C}(\mathrm{RQ}<0.4)$ and the least at $10^{\circ} \mathrm{C}( \pm 0.6)$ for both studied cultivars ('Gordal' and 'Manzanilla'), indicating that above $10{ }^{\circ} \mathrm{C}$ sugars were not the only respiratory substrate consumed. The respiration rate increase for a $10{ }^{\circ} \mathrm{C}$ rise in temperature, or Q10, were similar in both studies, with values between 1.7 and 2.0 for the green and black 'Conservolea' [68] and a range between 1.2 and 2.5 for the 'Gordal' and 'Manzanilla' varieties [81] in the temperature intervals considered.

Once the fruit is detached, the concentration of substrates for respiration becomes limited. When stored at room temperature these substrates are consumed continuously, while when refrigerated this consumption is reduced. When brought at $20^{\circ} \mathrm{C}$, this fruit still disposes of a higher concentration and therefore, higher $\mathrm{CO}_{2}$ production levels can be expected. This phenomenon is clearly illustrated in the study of Plasquy et al. in which the respiration rate is followed during 14 days of storage for three varieties ('Arbequina', 'Picual' and 'Verdial') at ambient temperature and $5{ }^{\circ} \mathrm{C}$ [45]. Meanwhile, higher respiration rates were observed when the fruit was damaged during the harvesting. The fruit of two studied varieties ('Manzanilla de Sevilla' y 'Manzanilla Cacereña'), harvested with a grape straddle harvester, showed a higher respiration rate than the hand-picked ones [43]. Similarly, higher $\mathrm{CO}_{2}$ production was reported in naturally bruised 'Manzanilla' olives when compared to healthy [84].

\subsection{Ethylene Production}

Ethylene production during cold storage was significantly higher for mechanically harvested olives and equally attributed to the damage caused by the harvester [43]. A similar result was obtained by [45], who reported a significant effect of the harvesting method when comparing the traditional harvesting that implied the dragging of nets with olives over the ground, with a gentler picking using a manual inverted umbrella [45]. the ethylene production rate in green olives was almost undetectable for the duration and temperatures tested when manually picked olives were compared [68]. The black ones, on the contrary, showed a 10-fold increase in ethylene production between 0 and $10^{\circ} \mathrm{C}$, indicating that the critical temperature for its synthesis is below $10^{\circ} \mathrm{C}$. This result was in line with earlier published studies that demonstrated the significant effect of ripening on the biosynthesis of ethylene at ambient temperature $[9,85,86]$.

\section{Physico-Chemical Analysis of the Extracted Oil}

Most of the published studies included a physicochemical analysis of the oil extracted from cold-stored fruits. As a minimum, this includes the official parameters as shared by 
the European Commission [87], the International Olive Council [1] and the US Department of Agriculture [88] comprising the level of free fatty acids, expressed as the \% oleic acid; the peroxide value (PV), expressed in $\mathrm{mEq}_{2} / \mathrm{kg}$ oil; and the absorbance at 232 and $270 \mathrm{~nm}$. Additional parameters such as the oxidative stability expressed as the oxidative induction time (h), the chlorophyll and carotenoid pigment profile, and the bitterness index are often included. A specific focus on the minor components of the oil implies the detection and quantification of the kind and amount of polyphenols, tocopherols, volatile compounds (VOC) and alkyl esters.

\subsection{Level of Free Acidity}

Free fatty acids (FFA) are produced by the hydrolysis of the oil-induced by lipolytic enzymes. These enzymes are normally present in the pulp and seed cells of the olive. When the integrity of the fruit is lost, the enzymes react with the oil that is contained in vacuoles. Unhealthy, damaged or bruised olives, together with detriment storage conditions are the main sources for high values of FFA. The amount of FFA is expressed as the percentage of gram of oleic acid per $100 \mathrm{~g}$ of oil. The maximum level for extra virgin olive oil (EVOO) is set at $0.8 \%$. The level of acidity is always present as one of the key parameters to evaluate and compare the different storage conditions. Not only because it is one of the decisive elements in enhancing the quality of the oil, but also because of its sensitivity in detecting changes in the investigated oils. The published reports leave no doubt that the increase in the acidity level is positively related to the storage temperature as well as the period of time $[10,11,17-20,26,27,30,31,34,39-44,46,47,49,51,55,57,89]$.

The combined effect of mechanized harvesting of olives for the mill and the conservation method was the subject of several studies $[30,39,43,46]$. The acidity of the oil produced from olives harvested with a combine harvester was, after 4 days and regardless of the storage temperature, higher when compared with the values of the oil obtained from fruits harvested by hand [39]. However, it was pointed out that the mechanization of the harvest does not compromise the quality of the oil produced from olives of the 'Picual' variety, although it is also not denied that an effect on certain other varieties such as 'Koroneiki' and 'Barnea' is possible [30]. Gently harvested olives maintained low FFA values over the storage period; however, hand-held combs, increased significantly after 1 week and hand-held machines even evolved above the $0.8 \%$ limit after 1 week. Fruit harvested with

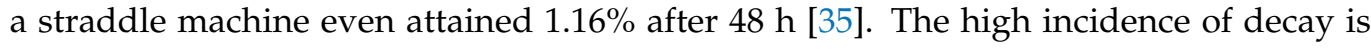
brought forward as the main reason why the acidity levels were significantly higher in oils extracted from mechanically harvested olives, although a varietal difference was noticed between the studied varieties [43].

When the time it takes to exceed the level of $0.80 \%$ is compared, the variety 'Picual', preserved at $5{ }^{\circ} \mathrm{C}$ needed between 23 [30], more than 30 [38] and up to 45 days at $1.00 \%$ [17,18]. The 'Coratina' variety was maintained for up to 30 days at $5{ }^{\circ} \mathrm{C}$ a FFA level below $0.8 \%$ [31]. Olives of the 'Arbequina' variety, stored at $3{ }^{\circ} \mathrm{C}$ and harvested with a harvester, exceed that threshold after 10 days, while when hand-picked, they reach up to 3 weeks [39]. The 'Verdial' variety was stored for more than 30 days at $5{ }^{\circ} \mathrm{C}$ before it exceeded $0.8 \%$ [38].

The intervarietal differences concerning the level of acidity were also noticed among three Portuguese varieties [47], among the 'Picual', 'Barnea' and 'Koroneiki' varieties [30], and between 'Arbequina' and 'Arbosana' [42]. Regarding the effect of the used harvesting and conservation method for the 'Arbequina' variety, conservation became prominent after four days of storage, while the 'Picual' cultivar showed to be more resistant to a rise in FFA. The 'Verdial' offered a more confusing profile. While in the first year an increased importance of the conservation method was measured, this effect was absent in the second year while the harvesting method was responsible for $30-60 \%$ of the variance [46].

Differences between the ripening stage were also observed. Comparing green mature, veraison and black olives of the 'Picual' cultivar during a storage period of 4 weeks at $5{ }^{\circ} \mathrm{C}$, the green mature stayed below $0.8 \%$ up to 4 weeks, the veraison and black olives attained levels above $0.8 \%$ after, respectively, 3 and 2 weeks [44]. 


\subsection{Peroxides}

Peroxides are the primary products of the oxidation of olive oil. Peroxide value (PV) is a measure of total peroxides in olive oil expressed as $\mathrm{mEq}_{2} \mathrm{~kg}^{-1}$ oil and hence a major guide of quality. None of the published studies exceeded de maximum value of $20 \mathrm{mEq} / \mathrm{kg}$ oil when cold-stored. Notwithstanding, significant differences were observed due to the specific conditions of conservation.

After one week, a sharp rise in the peroxide value was observed up to 30 days at ambient temperature and $8{ }^{\circ} \mathrm{C}$, followed by a decrease until 60 days. At $5^{\circ} \mathrm{C}$, the increase was lower and spread over 45 days [19]. Other authors reported an increase of the PV only for olives stored at $7.5^{\circ} \mathrm{C}$ after 30 days [27]. Values higher than $20 \mathrm{mEq}$ were registered in olives stored at 2 weeks after which a decline set in, probably due to the consumption of minor compounds as phenols and tocopherols that make the formation of peroxides difficult [47]. The initial increase followed by a decrease was attributed to the formation of secondary carbonyl compounds [89]. The storage conditions do play a significant role. A doubling of the PV was observed after 11 days when stored in plastic bags, while only after 25 days in plastic containers [51]. The effect of the ripeness of the fruit on the PV values was also reported [44]. A clear difference between on the one hand 'Arbequina' and 'Picual', and on the other 'Verdial' was noticed [46]. The latter attained the PV limit in one week when recollected with nets. The harvesting method stood out as the most influential factor for all varieties.

\section{3. $\mathrm{K} 270$ and $\mathrm{K} 232$}

UV-specific extinction determination permits an approximation of the oxidation process in unsaturated oils. At $232 \mathrm{~nm}$, primary oxidation products show absorption (conjugated peroxides) which increase due to inappropriate storage of olive fruits or a defective extraction. At $270 \mathrm{~nm}$ secondary oxidation products, such as carbolynic compounds (aldehydes and ketones) are detected which indicates an advanced oxidation process. The maximum permitted values are 2.5 for K232 and 0.20 for K270. The results obtained in relation to the degree of oxidation as measured by these parameters are in line with the one observed with the peroxide values, with only a few studies reporting values that exceeded the set limits even when the fruit was cold-stored for more than a month.

The values of K232 and K270 remained practically constant when stored at $5{ }^{\circ} \mathrm{C}[10,26,27,31,34,40-42,55]$. An increase in K232 and K270 at 15 days at ambient temperature was observed, surpassing the limits at 30 days [11]. 'Picual' olives, stored in plastic containers of $64 \mathrm{~kg}$ of fruit for two months, attained the maximum limit after 14 days when stored at ambient temperature, 33 days at $8{ }^{\circ} \mathrm{C}$. At $5{ }^{\circ} \mathrm{C}$ the limit was not yet reached at the end of the experiment. similar values for $\mathrm{K} 232$ were obtained at different temperatures up to 30 days [19]. From then on, the samples differed significantly with the lowest values found in oils from olives stored at $5{ }^{\circ} \mathrm{C}$. At $270 \mathrm{~nm}$, and in contrast with the earlier published study [10], the storage temperature showed to significantly affect the presence of carbonylic compounds. [29] on the other hand, observed a significant effect of the K232 but not on the K270. In the same manner, [89] registered an increase of K232 after 7 days, regardless of the storage temperature, and all values surpassing the limit except when stored at $5 \%$ and kept a low $\mathrm{O}_{2}$ concentration. The values of $\mathrm{K} 270$ showed a significant effect of storage temperature but all values were above maximum.

Mechanical harvesting exerted a significant effect on the K232 and K270 values of the extracted oils. The higher values observed led to an increase in the amount of conjugated fatty acids, meanwhile this process was accelerated at a storage temperature of $18^{\circ} \mathrm{C}$ [39]. For the values of K270, no significant differences were found initially. However, in oils from mechanically harvested olives an increase took off after 4 days of storage at $3{ }^{\circ} \mathrm{C}$, while no difference was observed in the oils extracted from manually harvested fruit. This was attributed to the internal rupture of the olive during the crushing in the course of the harvest. Similar changes were not reported in a recent research [46] as no significant effect for K232 was detected. At $270 \mathrm{~nm}$, the effect of the harvesting method was significant in all 
the varieties. These results indicate that the damages provoked by a harvester are even more severe than those that occur when olives are picked from the ground. However, other authors did not observe the K232 and K270 values to be affected by the variety, type of harvesting and storage time [30,43]. Opposed results were reported, pointing to a varietal difference in the Portuguese cultivars for K232, but obtaining at $270 \mathrm{~nm}$ similar values [47]. Olives in open perforated boxes behaved better, as only after 17 days the limit value for K232 was attained [51]. In plastic bags, a drastic increase was observed, without of the limit values after 11 for K232 and 25 days for K270. Significant changes in the K270 due to the time of storage were showed [44]. After one week, green mature fruits exhibited higher values, while no changes were found in riper olives. The values of K232 on the other hand remained constant.

\subsection{Oxidative Stability}

The oxidative stability, measured with the Rancimat system, although it is not considered as one of the legally established parameters to evaluate the quality of the oils, provides an interesting estimate of the shelf life of the oil. A wide range of studies shows that the levels of oxidative stability are highly influenced by the genetics of the fruit. It is also accepted that not only the values within each variety are reduced during its conservation, but also that this process slows down when the fruits are subjected to low temperatures. Several studies have pointed out that up to at least 21 days, the values obtained with the Rancimat method did not change. Oils stored at $5{ }^{\circ} \mathrm{C}$ lost $35 \%$ of stability after 60 days of storage, while at $8{ }^{\circ} \mathrm{C}$ and ambient temperature, 70 and $93 \%$, respectively [19]. The resistance of 'Koroneiki' oil to oxidation did not change at $5{ }^{\circ} \mathrm{C}$ in air during 30 days of storage [27]. It was reported that the stability was slightly reduced $(<10)$ after 6 weeks of storage, which was seen as normal because fruit matured, and the stability decreases with olive maturation [38]. A reduction of $7 \%$ was also observed after 3 weeks of storage at $5{ }^{\circ} \mathrm{C}$ with the Tunisian cultivars 'Chemlali' and 'Chetoui' [49]. A slightly deviant result was obtained by Pereira et al., reporting a significant decrease during the first week of storage at $5{ }^{\circ} \mathrm{C}$, although a difference between the varieties 'Cobrançosa' on the one hand and 'Madural' and 'Verdeal Transmontana' on the other was also noted [47]. Similar intervarietal differences were observed by Rinaldi et al. and Plasquy et al. [32,46]. In the latter study, the harvesting method showed to be of major importance for up to 4 days. Over 14 days, the strength of the used conservation method increased, although the maximum and rate varied along with the cultivars. In 'Arbequina' it attained almost $80 \%$ on day 14 , in 'Verdial' $40 \%$ and 'Picual' $20 \%$. In the same line, varietal differences with the lowest values for the mechanically harvested olives were reported [39,43].

A bad correlation between PV and stability was observed [11], suggesting the existence of other factors in addition to oxidation state that influence stability. The high concentration of free fatty acid oils extracted from fruit stored at ambient temperature underwent a remarkable decrease after 30 days while at $5{ }^{\circ} \mathrm{C}$ the stability was constant. The temperaturedependent loss of stability was attributed to thermocatalyzed hydraulic and oxidative processes, which act on the oil contained in the olives during their ripening, either as a consequence of their own metabolism or as a result of a pathogenic activity [19]. Meanwhile, the detected correlation between the total amount of phenols and the induction times points to the antioxidant activity of hydrophilic phenols $[31,65]$.

\subsection{Chlorophyll and Carotenoid Pigment Profile}

The spectrometric detection of carotenoid and chlorophyll pigments at 460 and $670 \mathrm{~nm}$, respectively, was not reported systematically. The main interest to study their evolution during cold storage consist of them being active as an antioxidant and their key role in the oil color, a factor that influences the choice of the consumer [90].

The interpretation of the results turned out to be very difficult given the complexity of factors that are involved and the varietal differences. A stable carotenoids content in the oils extracted from the 'Manzanilla' cultivar stored during 5 weeks at $5{ }^{\circ} \mathrm{C}$ was registered, 
while the 'Picual' and 'Verdial' cultivars presented a clear reduction of carotenoids during the first 3 weeks [38]. In the following 2 weeks, the level of the 'Picual' increased to attain the initial values, while the 'Verdial' increased only slightly. The chlorophyll content of the 'Picual' and 'Manzanilla' increased continuously during the first 6 weeks after which a steep decrease was observed for the 'Picual'. On the other hand, 'Verdial' showed more than $40 \%$ loss of chlorophyll content after the first week and from then on the same level was maintained. A decrease of chlorophyll in 'Koroneiki' olives was observed when stored below $7.5^{\circ} \mathrm{C}$, although did not register any change over 60 days when stored at $5{ }^{\circ} \mathrm{C}$ [27]. In the same line, only a slight decrease in carotenoids as well as chlorophyll content over 3 -week storage at $5{ }^{\circ} \mathrm{C}$ was registered [49], while reported an increasing trend during the cold storage time [34]. The profile of the chlorophyll carotenoid content did not show significant differences in the Croatian varieties at ambient temperature and $4{ }^{\circ} \mathrm{C}$ [58]. Only those stored at $-20^{\circ} \mathrm{C}$ showed a significant change in both pigments. As the chlorophylls decreased, the level of carotenoids increased.

The erratic character of the results was also present in the studies that focused on the effect of the harvesting method. After 3 weeks of storage, the content of photosynthetic pigments became significantly higher in the manually harvested 'Arbequina' olives [39,70]. The phenomenon was attributed to a possible decrease in the consistency of the chloroplast wall, facilitating the release of the pigments in the oil. Similar results were found for the 'Manzanilla de Sevilla' but, at the same time, the 'Manzanilla Cacereña' showed a completely different profile [43]. The quantification of the effect of the harvesting and conservation method revealed significant differences among 'Arbequina', 'Picual' and 'Verdial' cultivars [46]. In 'Arbequina' the impressive importance of the storage method, explaining $80 \%$ of the variance from day 4 to 14 , was placed against the results of the 'Picual' variety, where the importance of the conservation was only visible in the first year, showing a linear growth from the onset to the importance of $80 \%$. In 'Verdial' the storage sensitivity was illustrated by a steep increase from day 4 to 8 , explaining $90 \%$ of the variance for one year. In the other year, a shift toward the importance of the interaction of the factors harvesting and conservation (40\%) was observed from day 8 up to day 14 .

\subsection{Bitterness Index (BI)}

The significant correlation between the intensity of bitterness, as evaluated in a sensorial manner by a panel, and the measurement of the absorbance at $225 \mathrm{~nm}$ [82], inspired several research groups to follow the progress of this parameter throughout a cold storage period.

A sharp decrease of $\mathrm{BI}$ in the oils obtained from olives stored at ambient and $8{ }^{\circ} \mathrm{C}$ was found, while the ones stored at $5{ }^{\circ} \mathrm{C}$ only presented a slow decrease [19]. Similarly, 8-day storage at $20^{\circ} \mathrm{C}$ led to a reduction in $\mathrm{K} 225$ of $58 \%$ in the monolayered olives and 4 -fold in the case of layers up to $20 \mathrm{~cm}$. At $10{ }^{\circ} \mathrm{C}$ the same results were obtained after 14 days. Notwithstanding this difference, the K225 index was reduced by $80 \%$ in all storage conditions at 20 days of storage [40]. The same gradual decrease was observed in 'Chemlali' stored for 4 weeks at ambient temperature. This progress was attributed to alternations or partial or total inhibition of the specific enzymes (glycosidases and estearases) which downplay the presence of secoiridoid derivatives of phenols and consequently the bitterness intensity [91]. A divergent result was also reported, indicating an initial increase of the K225 values for 'Chétoui' olives stored at $5{ }^{\circ} \mathrm{C}$, in air or under CA. After two weeks, a decrease set in and a similar value was obtained for both conditions [89].

The magnitude of the effect of the harvesting and conservation methods used indicated varietal difference [46]. The 'Arbequina' cultivar showed to be the most vulnerable to the storage temperature from day 4 on, with conservation being the factor that explained up to $71 \%$ (year 1 ) and $83 \%$ (year 2) after 14 days. 'Picual' maintained a high explanatory power of the harvesting method for up to 14 days. 'Verdial' expressed a steady increase of the factor 'conservation', which attained a maximum above $60 \%$ at the end of the experiment. 


\subsection{Phenolic Content}

The phenolic content of olive fruit depends greatly on the characteristics of the cultivation zone, the climatic conditions and the different techniques applied during the production, the harvest and the postharvest treatment [92]. During ripening, their amount increases to attain a maximum at veraison after which a decline starts. The phenolic composition of the olive fruit is overly complex, although three secoiridoid glucosides form the major part: oleuropein, ligustroside and demetyloleuropein. When the cell tissues are ruptured during grinding, these hydrophilic components contact with specific enzymes that catalyze and modulate the formation of hydrolyzed secoiridoid derivatives. These oilsoluble substances play not only an important role as antioxidants but also in the formation of the sensorial attributes of the oil. Once again, numerous phenolic compounds have been detected although the 4 most important are the aldehydes of the aglucones of oleuropein and ligustroside (3, 4-pHEA-EA and p-HPEA-EA and, through the mediation of specific $\beta$-glucosidases, dialdehydes of the same dimethylised aglucones (3, 4-pHPEA-EDA and p-HPEA-EDA) [93]. During extraction, the phenolic compounds undergo processes of oxidation, either by free radicals or through the enzymatic activity of polyphenol oxidase (PPO) and peroxidase (POX), that are equally liberated during the grinding. The final content of secoirridoids results of the equilibrium between the processes of hydrolysis, catalyzed by the $\beta$-glucosidases and the oxidation processes induced by the PPO and POX enzymes [93].

Their specific role as antioxidants and their critical contribution in the bitter and pungent taste of the oils attained escalating attention within the cold storage research. In addition to an interest in the evolution of the total phenol content under specific storage conditions, the focus was brought towards shifts in the polyphenol's profiles, the evolution in the activity of the different enzymes and the prospect to modify the bitterness of the extracted oil through a modification of the temperature and/or CA [61].

The reported total amount of phenols measured in the extracted oil was determined by a colorimetric method using a Folin-Cicalteau reagent and expressing the amount as ppm of caffeic acid; gallic acid equivalents; p-hydroxyphenolacetic acid and o-coumaric acid. The separation of olive oil phenolic compounds has been achieved by the application of all types of liquid chromatography and gas chromatography [94].

The majority of the studies observed a significant delay in the decrease of total polyphenols $[16,27,29,31,33,34,39,40,49,57,58,62,95]$. Nevertheless, varietal differences were equally reported and even contradicted the general trend $[30,46,89]$. The phenolic compounds of 'Manzanilla de Sevilla' and 'Manzanilla Cacereña', even stored at $2{ }^{\circ} \mathrm{C}$, were strongly and negatively affected, especially those which were mechanically harvested [43]. Similarly, but less explicitly, a significant difference in the oils extracted from mechanically harvested fruit was registered [70].

Measurements of the phenols content in the fruit during cold storage elucidated the importance of the oxidation process of the phenols. More specifically, changes in oleuropein were reported that could only be explained by the effect of exogenous enzymes produced by microbial growth $[29,40]$.

Monitoring POX, PPO and $\beta$-glucosidases in crude protein extracts during fruit ripening and storage revealed different trends of activities for different cultivars and storage conditions [53]. A significant reduction of the PPO during the first 2 days of storage was reported, and from then on, a gradual decrease [33]. POX showed a gradual decrease over the 7 days of storage at $15^{\circ} \mathrm{C}$. However, the fact that a multitude of factors (aerobic conditions, storage time and temperature, ripeness, initial quality and microbiological state, varietal resistance against microbiological attack) could influence the production of volatile phenols make it extremely difficult to isolate and describe their complex chemical nature $[41,42,93]$. 


\subsection{Volatile Compounds}

The volatile compounds of virgin olive oil are primarily generated during the extraction process. Most of them are aldehydes and alcohols of six and five straight-chain carbons $(\mathrm{C} 5, \mathrm{C} 6)$ together with the corresponding esters, and are synthesized through the enzymatic lipoxygenase (LOX) pathway [95]. However, the handling of olive fruit and consequent storing can result in progressive cell disruption, increased enzymatic activity and ultimately a modification of the oil sensory quality. It is suggested that the premature activation of the LOX pathway alters not only the biochemical status of the fruit but also the amount of volatiles produced during the milling step [43].

While the total amount of volatiles decreases throughout the storage time it is equally true that the different $\mathrm{C} 5$ and $\mathrm{C} 6$ volatile compounds showed to evolve differently over the storage period, making a detailed interpretation difficult if not impossible [29,40]. Moreover, negative volatile compounds are formed from the metabolic action of yeast and molds [40].

Fruit damage caused by mechanical harvesting triggered the formation and emission of volatile compounds during storage, leading to a decrease in the amount of total volatiles found in the oils. After $24 \mathrm{~h}$ of storage, a significantly lower content in C5 and C6 compounds between the mechanically and hand-harvested olives was found, however, these differences were minimized after 11 days [43].

The evolution of the activity of LOX-derived volatiles under different storage conditions showed to be highly variety dependent. No significant differences were reported in the presence of $\mathrm{C} 6$ aldehydes and alcohols in the oil of 'Chétoui' variety when related to the olive ripening and storage [52]. Quite different results were obtained with 'Arbequina' olives, where the compounds were much higher in the oil from fruit with the same ripening but stored at $25^{\circ} \mathrm{C}$ when compared with those at $5^{\circ} \mathrm{C}$. It is suggested that these high amounts are due to the rapid fruit degradation and cell disruption due to the higher storage temperature [52].

\subsection{Tocopherols}

Tocopherols $\left(\alpha_{-}^{-}, \beta_{-}^{-}, \gamma_{-}^{-}, \delta_{-}\right)$belongs, together with tocotrienols $(\alpha-, \beta-, \gamma-, \delta-)$, to a group of plant soluble lipid compounds known as vitamin E. The antioxidant effect of tocopherols depends mainly on the temperature and lipid composition. $\alpha$-Tocopherol is the most common form of vitamin $\mathrm{E}$ with the highest biological activity, representing $95 \%$ of the total tocopherol content in olive oil. The content of tocopherols is shown to be cultivar dependent and significantly affected by the harvesting system, fruit ripeness, crop year, the storage temperature and the storage time $[39,43,46,96]$.

Fruit cold storage does delay the degradation of the tocopherols but cannot avoid it. A significant decrease in tocopherol when fruit was stored at $3{ }^{\circ} \mathrm{C}$ was reported as well as significant differences between three Portuguese cultivars [47]. Similarly, a significant effect of the cultivar was reported, comparing 'Ottobratica' and 'Carolea', as well as of the storage temperature on the total amount of tocopherols [34]. A focus on the effects of the harvesting methods revealed that the oil extracted from manually harvested fruit significantly contained higher values when compared with the mechanically harvested, regardless of the storage temperature [39]. At the same time, the fruit stored at $3{ }^{\circ} \mathrm{C}$ resulted in values that were significantly higher than when stored at $18{ }^{\circ} \mathrm{C}$, regardless the system of harvesting. A significant effect of the harvesting method was reported but specified the presence of an extreme difference after one day of storage, although this discrepancy equalized after 6 days [43]. It was suggested that the internal damage caused in the fruit during mechanical harvesting, was responsible for the extremely rapid oxidation of tocopherols). A significant effect of the storage time and the harvesting method on the amount of $\alpha$-tocopherols in three varieties ('Arbequina', 'Picual' and 'Verdial') was observed [46]. However, the effect of the conservation method was absent in both studied years in the 'Arbequina' and 'Verdial' cultivars and only in one year in the 'Picual'. The strength of the factor 'harvesting' varied between the two years and among the varieties. 


\subsection{Alkylic Esters}

The extraction of oil from olives in which fermentative processes have started gives place to negative attributes, such as musty, winey-vinegary or muddy sediment. These sensory classifications were related to the content of free acid alcoholic ester's (FAAE) in the olive oil [97]. It was further observed that very high concentrations of FAAEs in the olive oil do reflect fermentative defects of the olive fruit, whereas other defects, such as oxidative ones or frozen olives, do not produce FAAEs [98]. FAAEs are formed by transesterification of free fatty acids with short-chain alcohols, mainly methanol and ethanol yielding methyl (FAME) and ethyl esters (FAEE), which are both extracted with the oil. However, while the methanol is also formed during the pectin degradation of the cell wall during the ripening of the olive fruit, the ethanol can only be produced by fermentation, except specific varieties that have been shown to produce ethanol during their ripening [99]. Since 2013, FAEE are considered as an important marker and as such included in the EU Commission Regulation [100].

Inappropriate practices during the harvest and storage of olives are important factors that do promote their hydrolytic and oxidative deterioration. The content of ethanol in ground-picked olives was significantly higher compared to fruit harvested from the tree [101]. However, the amount of ethyl esters in the extracted oil remained below the limit established for EVOO and was attributed to the short time between the recollection and the extraction which impeded the synthesis of higher concentrations [101]. The type of container used during post-harvest storage showed to be a relevant factor in explaining the high levels of FAEE when olives, stored in closed plastic bags, were compared with those kept in perforated plastic boxes [51].

Thus far, the presence of FAAE have been studied scarcely. A manifest effect of the olive storage temperature on the FAME and FAEE content was observed [34]. The limits of FAEE for EVOO $(<30 \mathrm{mg} / \mathrm{kg})$ was surpassed after 12 days of storage at $25^{\circ} \mathrm{C}$. When stored at $4{ }^{\circ} \mathrm{C}$, one variety, 'Carolea', showed no increase of neither of the esters. The other variety, 'Ottobratica', showed a significant difference when two harvesting moments were compared. The latter harvested fruit attainted a level above the set maximum, indicating that the physical state of the drupes was declining and the aptitude to deterioration increasing. No significant differences were found in the treatments in the studied 'Rosignola' variety [58]. In the other variety, 'Istarska Bejelica', only an increase in the oils stored at room temperature was observed [58].

\section{Fruit Temperature Management}

\subsection{Rationale for Controlling Postharvest Olive Fruit Temperature}

The primary objective of cold storage of olive fruit was to spread the extraction process over a longer time to increase the processing capacity. The research was oriented to determine the maximum storage time of the fruit without jeopardizing the quality of the oils extracted therefrom. However, as the oil industry opted to amplify the production capacity, the proposed conservation method was introduced only sporadically. Subsequently, the fruit temperature was modified to induce precise characteristics of the extracted oil. Yet, the challenging technique came along with specific constraints and thwarted its incorporation at an industrial level. Currently, the olive oil industry is facing various new challenges that directly relate to the control and the modification of the fruit temperature. Climatological changes are provoking a shift in the phenology of the olive plant and are forwarding the optimum harvest time by several weeks [102,103]. Meanwhile, high-density orchards (HDO) do request specific varieties, such as 'Arbequina', 'Koroneiki' and 'Arbosana', which need to be harvested early in the season [104]. Finally, the success of fresh-flavored oils for the gourmet market, backed up by the growing importance of the international olive oil competitions, favors an early harvest [105]. Consequently, a harvesting campaign that envisions high-end quality olive oil is taking off in September, with day temperature that easily raises above $30^{\circ} \mathrm{C}$. 
Forwarding the harvest leads unavoidably to a high field temperature of the fruit. This undesirable situation, when combined with a transport of a couple of hours in trailers of more than $10 \mathrm{t}$, during which the fruit temperature further increases, suffice to create conditions of asphyxia and induce anaerobic respiration. Consequently, processes of fermentation produce by-products that lead to detectable sensory defects and high levels of alcoholic esters in the extracted oil and ultimately to the rejection of the oil as EVOO [106]. This new situation has already alarmed the industry. Nocturnal harvesting was introduced as a possible solution but soon after prohibited for its disastrous side effects on the birdlife [107].

But even without devastating fermentation processes during the transport and storage, a high field temperature of the fruit impedes the extraction of high-quality olive oil. It is widely accepted that the ideal malaxation temperature is situated between 25 and $30{ }^{\circ} \mathrm{C}[108,109]$. This becomes simply impossible with fruit at more than $25^{\circ} \mathrm{C}$, knowing that crushing itself rises the olive pasta at least $5{ }^{\circ} \mathrm{C}$ [110]. Under these conditions a full control of the malaxing parameters, essential to obtain the desired organoleptic characteristics of the oil, simply becomes impossible.

Up to now, controlling the temperature during the transport of the olives was hardly taken into consideration, similar to the necessity to adjust the temperature before the extraction process. Once the fruit was harvested, it was brought to the mill and extracted immediately if possible and stored for a short time when necessary. The mentioned environmental, agronomical and cultural factors are bringing the existing postharvest model under stress and urge for a more dynamic way to control the fruit temperature from the moment it is harvested up to its processing.

Developing specific cooling installations adapted to the different stages of the postharvest stages and production lines, do have in common the need to know the specific physiological and biothermal characteristics of the fruit. Several studies have been published in this respect and do confirm that olive fruit can be cooled to the desired temperature in a time of several minutes either by water or cooled air, without compromising its quality [111-113].

\subsection{Biothermal Characteristics}

Determining the cooling time needed to reach the desired temperatures is the first necessary step in the design and/or implementation of any cooling system. Existing physical models have low applicability at the industrial level since it is very difficult to take into account the physical and biochemical variability of the fruit with the parameters they contemplate. Therefore, an effective way to obtain information about the cooling process is by making physical measurements in a real process.

Specific data concerning the thermodynamic properties of olive fruit remains scarce. Ref. [111] published data on the thermal conductivity (k), specific heat (Cp) and thermal diffusivity $(\alpha)$ of olive fruit but did not take into account the geometrical variability that exists among the varieties and used simplified mathematical equations to calculate the constants. The calculations of the $\mathrm{Cp}$ were based on the chemical composition of 4 different varieties while the thermal conductivity was measured using the transient hot-wire method. The thermal diffusivity was calculated using the experimentally determined values of $\mathrm{k}$ and $\mathrm{Cp}$. The results showed deviant results when comparing temperature-related models with empirical ones. A sophisticated mathematical model for heat conduction in stone fruits was developed to calculate the thermal properties of olive fruit [112]. The used empirical data stemmed in part from the precise measurement of the dimensions of one olive (c.v. 'Gordal') and the internal temperature change during its cooling in cold water. They calculated a Biot number of 4.43 using water as the transfer medium for an olive that weighed $10.44 \mathrm{~g}$, which is by all standards an extreme weight for olive fruit. The Biot number (Bi) expresses the ratio of the internal resistance of conduction to the external resistance of convection (h). When $\mathrm{Bi}<0.1$, the internal resistance is considered to be negligible in comparison with the surface resistance and it is assumed that the material or produce 
heats or cools down uniformly $[72,114]$. As the values for $\mathrm{h}$ are medium-dependent, the obtained Biot-number is not valid when considering a pre-cooling treatment with cooled air [115]. Submerging picked olives in a cooled solution of diluted lye is a recognized and recommended treatment to avoid bruise damage for table olives [116,117]. However, when dealing with fruit intended for oil extraction, contact with water before storage is not recommended as it prompts deterioration and even fermentation processes [118].

Thermal imaging was used to measure the temperature change of individual olives of six different cultivars stored under room cooling conditions and related the obtained results to their physical and geometrical characteristics [113]. Thermodynamic parameters were further used to simulate the cooling process of the olive fruit by convection within a range of field temperatures and room cooling temperatures. The calculated cooling rates revealed a non-linear relation between the specific surface area and the cooling rate of an olive, suggesting that underlying factors need to be considered when calculating the specific heat of the fruit. To explain the observed flattening on both sides of the curve, further research is needed to clarify the influence of the stone when dealing with small olive fruit, as well as the increased Biot number for heavier olives. Nevertheless, the simulation clarified that a relatively short time is needed to cool the fruit to a desirable temperature when placed in a cold air environment. In the case of 'Arbequina' and 'Koroneiki' cultivars, fruit with a field temperature of $38^{\circ} \mathrm{C}$ would attain a temperature of $22^{\circ} \mathrm{C}$ when kept in an environment of $-16^{\circ} \mathrm{C}$ for less than $2 \mathrm{~min}$. In the case of 'Hojiblanca' and 'Picual', the cooling time under these conditions increased to $3 \mathrm{~min}$. Finally, the heavier 'Verdial' and 'Gordal' varieties needed up to $5 \mathrm{~min}$ to cool down to the desired temperature. Even though further research is needed to discard negative impacts on the fruit, the obtained results are useful for the development and the introduction of new techniques based on cooled air. A related experiment in which boxes with $10 \mathrm{~kg}$ of olives were brought to $5^{\circ} \mathrm{C}$ by placing them at a room temperature of $-18{ }^{\circ} \mathrm{C}$, revealed no deterioration in the quality parameters of the oil [77].

The important role that forced air cooling can play in the field, at the farm and at the reception yard of the mill, does advocate for extensive studies on the application of this technique. More specifically, experiments at the laboratory level are needed to document the working of a cooling tunnel and to study the effect of the cooled forced air on the fruit characteristics and oil extracted therefrom. This implies the design of the laboratory scale cooling tunnel. An example of such a system is given in Figure 6. The showed system would imply the preliminary warming of the olive fruit in an incubator at a set temperature while the cooled air can easily be provided by a separate cooling group.

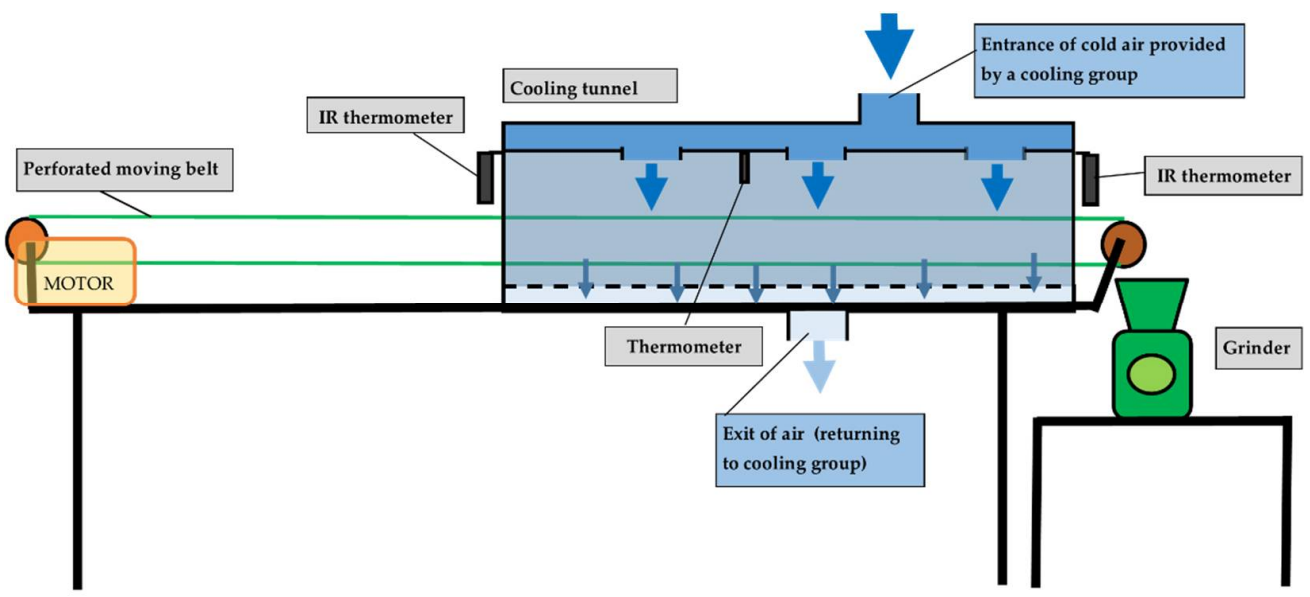

Figure 6. Experimental setup at laboratory scale to study the effect of cooled forced air on the quality of the fruit and the oil extracted therefrom. 


\subsection{Removing Field Heat}

The effect of time and temperature on respiration has been studied on various intact fruit as well as fresh-cut produce [75,119-123]. In all of these studies, an Arrhenius-type equation showed to be very reliable to describe the respiration rate in function of the temperature. The studies on the respiration rate of cold-stored olives fruit have shown that the respiration rate increases at a higher temperature. In addition, damaged or bruised fruit do not only accelerate respiration $[43,84]$ but also induces hydrolytic and oxidative deterioration. The presence of FAEE in the extracted oil does indicate the formation of ethanol during the transport or storage because of fruit damage as well as anaerobic respiration [51,101]. The rate of gas diffusion and respiration varies significantly when the fruit is piled up, as is the case when olives are collected and transported in large containers. Under such conditions, some parts risk becoming anaerobic while others remain aerobic.

Removing field heat as soon as possible stands as a compelling recommendation in the postharvest studies that focus on controlling the quality of the fruit $[74,124]$. The process of removing field heat is commonly referred to as precooling and implies the quick removal of heat, in a few minutes or a few hours, either in the field or at the processing plant. Prompt precooling is used for fruit and vegetables that need rapid cooling to maintain the high quality during the holding period. A delayed cooling, implying a lag between the harvest and the precooling treatment, generally reduced the quality and the storage life, although it is also reported that for specific fruits, such as cherry, peach, nectarine and apple, a cooling delay may be beneficial. Gradual cooling lowers the temperature of the fruit and vegetables to only certain degrees over hours or days to induce the cold tolerance in the produce.

Forced air cooling, hydro-cooling, liquid ice-cooling and vacuum cooling are the most commonly used precooling techniques [125-127]. All involve the fast transfer of heat from the produce to a cooling medium, such as air or water. However, the characteristics of the commodity and the container, the rate of cooling and the further storage conditions do define the most appropriate technique. Forced air-cooling is further differentiated in the circulation of cold air at a high velocity in refrigerated rooms, forcing cold air through bulk or stacked produce as they move through a cooling tunnel on a conveyer, and using the pressure differential technique that forces air through produce packed in containers.

When contemplating the possibilities to remove the field heat of harvested olives, at least three different circumstances need to be taken into account. Firstly, when there is a risk for fruit asphyxiation and fermentation processes during the transport and/or consequent storage. Secondly, when short-time storage before transport is necessary while the requested minimum amount of fruit for extraction is harvested. Thirdly, when the optimal extraction of the oil becomes impossible when the fruit arrives at the mill at a temperature already above the set maximum.

If the day temperature and transportation time are such that the respiration threshold will be attained before the processing of the fruit, prompt precooling come to the fore as the only solution to avoid deterioration in the batch of olive fruit. Water as a cooling medium can be excluded as wetting the olives before their transport will create even greater deterioration.

Forced air-cooling comes to the fore as a possibility and more specifically the use of a cooling tunnel in which the temperature of the fruit is lowered to at least $15^{\circ} \mathrm{C}$. The estimation of the cooling rates allowed to predict that this can be attained in the range of a couple of minutes [113]. However, the cooling mechanism needs to be capable to handle the considerable and continuous amount of olives that are harvested mechanically. Even though this looks not possible in the short term, it can be expected that either the next generation of straddle machines will include such a cooling extension or that the existing mobile pre-cooling facilities are adapted to the specific harvesting characteristics [125,128]. As the latter is designed to precool palletized produce, this would imply either the distribution of the harvested olives in containers or a rethinking of their design.

Cold storage for a short time at the farm can be provided using room cooling. The experience of a small-scale producer dealing with 5 to $6000 \mathrm{~kg}$ of olive fruit, harvested over a 
week, demonstrated already its feasibility $[45,46]$. However, natural convection air cooling is slow, especially when the room is very packed or when the olives are kept in $400 \mathrm{~kg}$ containers. In that case, it can take several days to lower the temperature to the desired $5{ }^{\circ} \mathrm{C}$. Storage in smaller plastic boxes filled with $15-20 \mathrm{~kg}$ of olives and providing sufficient space around and below each box to allow air circulation, thus becomes unavoidable. An important drawback of this method is the logistic problem it creates when hundreds of boxes need to be transported to the mill. Filling $400 \mathrm{~kg}$ containers before the transport offers a solution but it is obvious that a precooling treatment before storing them at $5{ }^{\circ} \mathrm{C}$ would be a far better solution. The possibility to precool a container of $400 \mathrm{~kg}$ has shown to be possible at laboratory level [77]. However, it would imply a small-scale precooling tunnel at the farm or a portable forced-air cooling unit in the field, as described elsewhere [128], to implement the system.

When the olives arrive at the mill at a temperature that impedes a proper malaxation, two possible options are available, either the fruit is cooled at arrival or just before the grinding, or the temperature of the ground olive paste is lowered before entering the malaxer. Cooling of the olive paste through a tubular heat exchanger before the malaxation process is suggested when the thermal conditions are above the optimal temperature to extract a high-quality EVOO [129]. The solution is presented as an alternative to the use of cold, climatic chambers or the use of dry ice, practices they discard as being not easily adaptable to an industrial oil transformation process [129]. Yet, the experiment was performed with olive fruit at a moderate temperature of $27^{\circ} \mathrm{C}$ that was cooled to $15^{\circ} \mathrm{C}$ followed by a malaxation at 25 and $30^{\circ} \mathrm{C}$. Neither the cooling time nor details of the heat exchanger (capacity, energy) were reported. The option to cool the fruit has not attracted the same attention until recently. During the harvest campaign 2020-2021 an experiment in a mill in the province of Jaen, planned to inject cold air using a turbine $(7.5 \mathrm{~kW})$ into hoppers with a capacity of 45 and 60 tons to eliminate sensorial defects, attributed to anaerobic fermentation in the produced oils [130]. At the same time, a new study was announced by a private olive mill to implement and evaluate the use of hydro-cooling to lower the fruit temperature of the incoming fruit [131]. Hydro-cooling is considered as one of the fastest precooling techniques and consists of immersing or flooding products in chilled water or by spraying chilled water over the product. According to the press release, the study uses a shower cooling system to lower the fruit temperature. To the best of our knowledge, the results of both studies are not yet published. In the first experiment, the crucial question will be whether the adapted forced air-cooling system can penetrate homogeneously the bulk of fruit in the hopper. Flow field uniformity is regarded as an important factor that affects not only the effectiveness and the energy consumption of forced air cooling [126]. Concerning the second experiment, it can be expected that hydrocooling will offer a suitable solution, however, this method can only be applied when the olives are processed immediately thereafter. The degree of olive damage at different points in the pre-processing steps in the mill increases from $28 \%$ at the reception to $59 \%$ after the washing and $78 \%$ during the storage of less than $12 \mathrm{~h}$. [118]. When washed olives are stored, their ethanol content increases significantly due to the loss of integrity of the fruit and the availability of oxygen in the hopper [132].

A third alternative might consist of the cooling of the fruit immediately after the fruit is cleaned from branches and leaves. This could be accomplished by installing a forced-air cooling tunnel right after this cleaning or, when space impedes such a structure, by converting the existing ramps of the moving belts into air-cooled tunnels. Eventually, this solution can also be used for precooling the fruit for subsequent cold storage. In that case, the cooled fruit can be collected in containers of $400 \mathrm{~kg}$, allowing traceability and easy portability towards the cooling room at the mill.

\subsection{Adjusting to Desired Preprocessing Temperature}

Even though removing the field heat or the cold storage of olives may be the ideal solution to maintain the fruit quality, it has one important drawback when the cold fruit 
needs to be processed. Similarly, to too warm olives, a too-cold temperature does impede proper malaxation and extraction [133].

The use of heat exchangers, microwave, ultrasound applications or combinations of them is presented as reliable solutions to adjust the temperature of the paste and to reduce the malaxing time [134-141]. Several models of heat exchangers are already on the market (Pieralisi Protoreattore, Alfa Laval EVO-line) while a sono-heat exchanger, being a combination of a heat exchanger and ultrasound technique, is expected to enter industrial production soon [142]. However, all these innovative flash heat treatments imply substantial investments, adjustments of the production lines and higher energy consumption [143].

The feasibility of warm-up olives during their immersion in the washing tub might be an economic alternative [144]. Experiments at the laboratory as well as pilot-plant level demonstrated that an immersion time between 15 and $20 \mathrm{~s}$ in water at $35-40{ }^{\circ} \mathrm{C}$ suffice to warm-up olives at $10{ }^{\circ} \mathrm{C}$ to the desired $27^{\circ} \mathrm{C}$. It was further demonstrated that the temperature of the paste when entering the malaxer, could be easily monitored with a thermostat and adjusted by turning the electric heaters in the washing tub on and off. These results look very promising. The used temperatures and immersion time are not expected to affect the biosynthesis of the olive aroma and neither will deteriorate the oxidative stability or lower the polyphenol content, as was the case in experiments that used water at $50{ }^{\circ} \mathrm{C}$ and $72{ }^{\circ} \mathrm{C}$ for 3 to $5 \mathrm{~min}$ to lower the bitterness of the fruit $[60,63,145,146]$. The energy cost to keep the water around $40^{\circ} \mathrm{C}$ will depend on the characteristics of the washing tub (capacity, isolation) and the ambient temperature. Direct heating with electric resistances or an external heat exchanger is suggested as feasible economic solutions, that can be introduced to an existing washing installation. The lower investment costs and the easiness to integrate it into an existing production line makes it a valuable alternative for the costlier flash heat treatments.

\subsection{Developing Innovating Plants}

A technology maturity assessment system used by Clodoveo describes the progress in developing innovating plants to improve the $\mathrm{VOO}$ extraction process [142]. It offers a clear overview of the different steps that need to be taken from an initial idea to a fully commercial application. It comprises 10 steps of which the first four are related to the validation of an idea, and two to the developing of a prototype, the validation of the prototype system and finally two related to the production stage. Applied to the suggested forced air-cooling system, the initial idea is formulated, part of the basic research published and the concept and the application formulated. Once sufficient stakeholders are found, the building of a small-scale prototype can start. When the results of the laboratory experiments confirm the validity of the idea, the building of a large-scale prototype cooling tunnel or the adaptation of existing systems comes to the fore as the next step. Meanwhile, the specific environmental conditions in which the cooling tunnel is supposed to be integrated will bring the adaptation of the existing movable cooling systems or the incorporation of a cooling tunnel in a straddle harvester under the attention of the engineers with a focus on field precooling systems. The promising result in using the washing water to adjust the fruit temperature before grinding can be evaluated similarly. Once again, the different steps in the progress can be expected to come with specific challenges. The preliminary experiments already made clear that controlling the temperature of the water remains to be solved together with the necessity to continuously sanitize the used water to avoid bacterial growth.

\section{Conclusions and Future Research Directions}

The presented research made clear that the beneficial effects of cold storage are widely accepted. Overwhelming evidence, build up over the last 30 years, underscore the influence of cold storage on the quality of the olive fruit and the official and frequently used quality parameters of the oil extracted from cold-stored olives. As such, storage at $4-6{ }^{\circ} \mathrm{C}$ made 
it possible to delay the further processing of olive fruit by up to 4 weeks. The use of CA is not recommended as it did not show beneficial advantages. However, these general recommendations do imply healthy fruit, harvested with minimal damage and stored in optimal containers impeding asphyxiation and allowing the removal of respiration heat. Moreover, the observed intervarietal differences with respect to the vulnerability of the fruit and the importance of the degree of ripeness further caution overgeneralization. When the quality expectations rise and the production of premium oil becomes the main focus the conclusions become even less straightforward and urge for a further disclosure of the impact on the different minor components. The effect of cold storage on the amount of minor components such as polyphenols, tocopherols and volatile components as well as the formation of ethanol in the fruit during cold storage still needs further clarification. The mechanisms behind the observed and the reported contradictory shifts in composition and amount, continue to trigger new research questions. The role of ethanol in the synthesis of FAEE on the one hand and the importance of the factor temperature in attaining the threshold for aerobic respiration urge for a deeper understanding of the metabolic shifts during and within bulk olive transports. The effects of pressure, temperature and time on respiration and eventually the production of ethanol are still to be disclosed. Realtime measurement during bulk transport of the temperature and atmospheric gases could provide the necessary data to further construct and validate mathematical models.

The impact of increasing the mechanization of the harvest on the quality of the fruit calls for additional monitoring, especially when new machines and techniques are introduced. At the same time, broadening the scope of investigation towards not only the harvesting techniques at an industrial level but also at a small-scale level will document in a more precise way the mutual influence between the used harvesting and storage methods. The influence of the type and capacity of the storage unit has been left undiscussed for too long. Two recent publications of did address this subject [71,77], but the first reported only the effects on the official quality parameters, while the second restricted the storage time to less than 1 day. Whether cold storage will ever be a used technique in the postharvest handling of olive fruit, will largely depend on its ability to manage large quantities and workable solutions to precool the olives.

Cold storage is not just a method to prolong the quality of the harvested olives but can also be regarded as an important link in a more broadly defined fruit temperature management. From this perspective, new aspects come to the fore that have hardly been investigated in the handling of olive fruit. Recognizing that the removal of field heat is the first essential step in this process urge for specific knowledge on the biothermal parameters of olive fruit, the characteristics of the heat transfers in the different cooling mediums, and not in the least the evaluation of the different methods on the fruit quality and the oil extracted therefrom. Even though the preliminary results of Plasquy et al. do indicate that air at $-18{ }^{\circ} \mathrm{C}$ can be used to precool olive fruit, it must be underlined that the experiments took place under room cooling conditions $[77,113]$. To the best of our knowledge, no data are available on the use of forced air for a controlled lowering of the olive fruit temperature.

Studying fruit temperature management demands a multidiscipline approach. The intertwining of agro-chemical and engineering facets needs input from each of these specialties. Thus far, the focus has been mostly on the physiological changes in the fruit and the chemical changes within the extracted oils. The further study of the biothermal characteristics of olive fruit as well as the development and adaptation of existing cooling devices count on specific engineering skills. The knowledge that has been build up in the field of fruit and vegetable conservation offers an impressive backing but does not suffice because of the idiosyncratic nature of the olive fruit harvest and fruit handling.

The final aim of fruit temperature management is a concise control of the temperature from the moment the olives fruit are harvested up to the moment the extraction process starts. This mission boils down to taking seriously the fact that olives are fruit and that virgin olive oil is nothing less than fresh fruit juice. Even though this phrase is often cited and partly substantiated the official definition, it is still too often overlooked and 
too easily taken for granted. However, the new climatological challenges, the increasing mechanization of the harvest and the demand for premium products are fueling a new awareness that the quality of the oil depends largely on that of the olive fruit. Keeping the quality of the fruit as optimal as possible thus becomes a logical conclusion, which acknowledges the key role that control of the fruit temperature plays in this process.

Author Contributions: E.P. is responsible for the conceptualization of this review paper. The authors state to have equally participated in the writing. All authors have read and agreed to the published version of the manuscript.

Funding: This research received no external funding.

Institutional Review Board Statement: Not applicable.

Informed Consent Statement: Not applicable.

Conflicts of Interest: The authors declare no conflict of interest.

\section{References}

1. IOC [International Olive Council]. Trade Standard Applying to Olive Oils and Olive Pomace Oil; COI/T.15/NC No 3/Rev. 16; IOC: Madrid, Spain, 2021. Available online: https://www.internationaloliveoil.org/wp-content/uploads/2021/07/COI-T15-NC3 -REV-16-2021-_ENG.pdf (accessed on 28 June 2021).

2. Maxie, E.C. Storing olives under controlled temperature and atmospheres. Calif. Olive Assoc. Annu. Tech. Rep. 1993, 42, 34-40.

3. Maxie, E.C. Experiments on cold storage and controlled atmospheres. Calif. Olive Assoc. Annu. Tech. Rep. 1964, $43,12-15$.

4. Woskow, M.; Maxie, E.C. Cold storage studies with olives. Calif. Olive Assoc. Annu. Tech. Rep. 1965, 44, 6-11.

5. Cantarelli, C. Nuove soluzioni al problema della conservazione delle olive: Contributi sperimentali. Riv. Ital. Sostanze Grasse 1965, $17,475-480$.

6. Petruccioli, G.; Montedoro, G.; Cantarelli, C. Nuove prospettive nella tecnología della conservazione delle olive destinate all'estrazione. Riv. Ital. Sostanze Grasse 1970, 47, 475-480.

7. Montedoro, G.; Garofolo, L. Caratteristiche qualitative degli oli vergini di oliva. Influenza di alcune variabili: Varietà, ambiente, conservazione, estrazione, condizionamento del prodotto finito. Riv. Ital. Sostanze Grasse 1984, 61, 157-168.

8. Petruccioli, G.; Parlati, M.V. Studies on olives storage before oil extraction. III Effect of Storage conditions of olives on the chemical and organoleptic characteristics of oils. In Third Subproject: Conservation and Processing of Foods-A Research Project (1982-1986); Abstract 20; National Council of Italy: Milan, Italy, 1987; pp. 83-84.

9. Kader, A.A.; Nanos, G.D.; Kerbel, E.L. Responses of 'Manzanillo' olives to controlled atmospheres storage. In Proceedings of the Fifth International Controlled Atmosphere Research Conference, Wenatchee, WA, USA, 14-16 June 1989; Volume 2, pp. 119-125.

10. García, J.M.; Streif, J. The effect of controlled atmosphere storage on fruit and oil quality of 'Gordal' olives. Gartenbauwissenschaft 1991, 56, 233-238.

11. Gutiérrez, F.; Perdiguero, S.; García, J.M.; Castellano, J.M. Quality of oils from olives stored under controlled atmosphere. J. Am. Oil Chem. Soc. 1992, 69, 1215-1218. [CrossRef]

12. García, J.M. Efecto del $\mathrm{CO}_{2}$ en la atmósfera de almacenamiento sobre la fisiología de la aceituna de molino. Grasas Aceites 1993, 44, 81-84. [CrossRef]

13. García, J.M. Efecto del $\mathrm{CO}_{2}$ en la atmósfera de almacenamiento sobre la calidad del aceite de oliva. Grasas Aceites 1993, 44, 169-174. [CrossRef]

14. Castellano, J.M.; García, J.M.; Morilla, A.; Perdiguero, S.; Gutierrez, F. Quality of Picual olive fruit stored under controlled atmospheres. J. Agric. Food Chem. 1993, 41, 537-539. [CrossRef]

15. Pérez-Camino, M.C.; García, J.M.; Castellano, J.M. Polar compound concentrations in virgin olive oils from stored cultivar Picual olive fruits. J. Agric. Food Chem. 1992, 40, 2260-2262. [CrossRef]

16. Maestro, R.; García, J.M.; Castellano, J.M. Changes in Polyphenol Content of olives stored in modified atmosoheres. HortScience 1993, 28, 749. [CrossRef]

17. García, J.M.; Castellano, J.M.; Gutiérrez, F.; Castellano, J.M.; Perdiguero, S.; Morilla, A.; Albi, M.A. Cold storage of mill olives. In Contribution du Froid à la Preservation de la Qualité des Fruits, Legumes et Produits Halieutiques: Actes du Sumposium; Bennani, A.L., Messaho, D., Eds.; Actes Éditions Rabat: Rabat, Maroc, 1994; pp. 77-86.

18. García, J.M.; Gutiérrez, F.; Castellano, J.M.; Perdiguero, S.; Morilla, A.; Albi, M.A. Storage of olives destined for oil extraction. Acta Hortic. 1994, 368, 673-681. [CrossRef]

19. García, J.M.; Gutiérrez, F.; Barrera, M.J.; Albi, M.A. Storage of Mill Olives on an Industrial Scale. J. Agric. Food Chem. 1996, 44, 590-593. [CrossRef]

20. García, J.M.; Gutiérrez, F.; Castellano, J.M.; Perdiguero, S.; Morilla, A.; Albi, M.A. Influence of storage temperature on fruit ripening and olive oil quality. J. Agric. Food Chem. 1996, 44, 264-267. [CrossRef]

21. Canet, M.; García, J.M. Repercusión de la frigoconservación de la aceituna de molino en el proceso de producción de aceite de oliva virgen. Grasas Aceites 1999, 50, 181-184. [CrossRef] 
22. García, J.M.; Yousfi, K. The postharvest of mill olives. Grasas Aceites 2006, 57, 16-24. [CrossRef]

23. Monteleone, E.; Caporale, G.; Lencioni, L.; Favati, F.; Bertuccioli, M. Optimizing of virgin olive oil quality in relation to fruit ripening and storage. In Food Flavors: Generation, Analysis and Process Influence; Charalambous, G., Ed.; Elsevier: Amsterdam, The Netherlands, 1995; pp. 397-418.

24. Gardiman, M.; Tonutti, P.; Pizzale, L.; Conte, L.; Carazzolo, A. The effect of hypoxic and $\mathrm{CO}_{2}$-enriched atmospheres on olive ripening and oil quality. Acta Hortic. 1997, 474, 525-530. [CrossRef]

25. Koprivnjak, O.; Procida, G.; Benčić, D.; Zelinotti, T. Effect of olive fruit storage in sea water on oil quality. Food Technol. Biotechnol. 1999, 37, 209-214.

26. Agar, I.T.; Hess-Pierce, B.; Sourour, M.M.; Kader, A.A. Quality of fruit and oil of black-ripe olives is influenced by cultivar and storage period. J. Agric. Food Chem. 1998, 46, 3415-3421. [CrossRef]

27. Kiritsakis, A.; Nanos, G.D.; Polymenopoulos, Z.; Thomai, T.; Sfakiotakis, E.M. Effect of fruit storage conditions on olive oil quality. J. Am. Oil Chem. Soc. 1998, 79, 721-724. [CrossRef]

28. Agar, I.T.; Hess-Pierce, B.; Sourour, M.M.; Kader, A.A. Identification of optimum preprocessing storage conditions to maintain quality of black ripe 'Manzanillo' olives. Postharvest Biol. Technol. 1999, 15, 53-64. [CrossRef]

29. Kalua, C.M.; Bedgood, D.R., Jr.; Bishop, A.G.; Prenzler, P.D. Changes in Virgin Olive Oil Quality during Low-Temperature Fruit Storage. J. Agric. Food Chem. 2008, 56, 2415-2422. [CrossRef] [PubMed]

30. Dag, A.; Boim, S.; Sobetin, Y.; Zipori, I. Effect of mechanically harvested olive storage temperature and duration on oil quality. Horttechnology 2012, 22, 528-533. [CrossRef]

31. Clodoveo, M.L.; Delcuratolo, D.; Gomes, T.; Colelli, G. Effect of different temperatures and storage atmospheres on Coratina olive oil quality. Food Chem. 2007, 102, 571-576. [CrossRef]

32. Rinaldi, R.; Amodio, M.L.; Colelli, G.; Clodoveo, M.L. Controlled atmosphere storage of 3 Italian cultivars of olives for oil production. Acta Hort. 2010, 857, 97-105. [CrossRef]

33. Zullo, B.A.; Di Stefano, M.G.; Cioccia, G.; Ciafardini, G. Evaluation of polyphenols decay in the oily fraction of olive fruit during storage using a mild sample handling method. Eur. J. Lipid Sci. Technol. 2014, 116, 160-168. [CrossRef]

34. Piscopo, A.; De Bruno, A.; Zappia, A.; Gioffrè, G.; Grillone, N.; Mafrica, R.; Poiana, M. Effect of olive storage temperature on the quality of Carolea and Ottobratica oils. Emir. J. Food Agric. 2018, 30, 563-572. [CrossRef]

35. Famiani, F.; Farinelli, D.; Urbani, S.; Al Hariri, R.; Paoletti, A.; Rosati, A.; Esposto, S.; Selvaggini, R.; Taticchi, A.; Servili, M. Harvesting system and fruit storage affect basic quality parameters and phenolic and volatile compounds of oils from intensive and super-intensive olive orchards. Sci. Hortic. 2020, 263, 109045. [CrossRef]

36. Gutiérrez, F.; Varona, I.; Albi, M.A. Relation of acidity and sensory quality with sterol content of olive oil from stored fruit. J. Agric. Food Chem. 2000, 48, 1106-1110. [CrossRef] [PubMed]

37. Luaces, P.; Pérez, A.G.; Sanz, C. Effect of cold storage of olive fruits on the lipoxygenase pathway and volatile composition of virgin olive oil. Acta Hort. 2005, 682, 993-998. [CrossRef]

38. Yousfi, K.; Cayuela, J.A.; García, J.M. Reduction of virgen olive oil bitterness by fruit cold storage. J. Agric. Food Chem. 2008, 56, 10085-10091. [CrossRef] [PubMed]

39. Yousfi, K.; Weiland, C.M.; García, J.M. Effect of harvesting system and fruit cold storage on virgin olive oil chemical composition and quality of superintensive cultivated 'Arbequina' olives. J. Agric. Food Chem. 2012, 60, 4743-4750. [CrossRef] [PubMed]

40. Inarejos-García, A.M.; Gómez-Rico, A.; Salvador, M.D.; Fregapane, G. Effect of Preprocessing olive storage conditions on virgin olive oil quality and composition. J. Agric. Food Chem. 2010, 58, 4858-4865. [CrossRef] [PubMed]

41. Vichi, S.; Romero, A.; Gallardo-Chacón, J.; Tous, J.; López-Tamames, E.; Buxaderas, S. Influence of olives' storage conditions on the formation of volatile phenols and their role in off-odor formation in the oil. J. Agric. Food Chem. 2009, 57, 1449-1455. [CrossRef]

42. Vichi, S.; Romero, A.; Gallardo-Chacón, J.; Tous, J.; López-Tamames, E.; Buxaderas, S. Volatile phenols in virgin olive oil: Influence of olive variety on their formation during fruit storage. Food Chem. 2009, 116, 651-656. [CrossRef]

43. Morales-Sillero, A.; Pérez, A.G.; Casanova, L.; García, J.M. Cold storage of 'Manzanilla de Sevilla' and 'Manzanilla Cacereña' mil olives from super-high density orchards. Food Chem. 2017, 237, 1216-1225. [CrossRef]

44. Petrón, M.J.; Timón, M.L.; Carrapiso, A.I.; Andrés, A.I. Effect of ripening and olive cold storage on oil yield and some olive oil characteristics. Riv. Ital. Sostanze Grasse 2018, 95, 255-259.

45. Plasquy, E.; Blanco-Roldán, G.; Florido, M.C.; García, J.M. Effects of an integrated harvest system for small producers on the quality of the recollected olive fruit. Grasas Aceites 2021, 72, e436. [CrossRef]

46. Plasquy, E.; Florido, M.C.; Sola-Guirado, R.R.; García, J.M. Effect of a harvesting and conservation method for small producers on the quality of the produced olive oil. Agriculture 2021, 11, 417. [CrossRef]

47. Pereira, J.A.; Casal, S.; Bento, A.; Oliveira, M.B.P.P. Influence of olive storage period on oil quality of three Portuguese cultivars of Olea Europea, Cobrançosa, Madural and Verdial Transmontana. J. Agric. Food Chem. 2002, 50, 6335-6340. [CrossRef]

48. El-Nagaar, N.I.; El-Saedy, R.M. Storage temperature and storage duration affect fruit and oil quality of Coratina, Manzanillo and Picual olives. Alex. Sci. Exch. J. 2010, 31, 137-154. [CrossRef]

49. Ouni, Y.; Nabil, B.Y.; Zarrouk, M.; Flamini, G. Influence of olive storage period on volatile compounds and oil quality of two Tunisian cultivars of Olea europea, Chemlali and Chetoui. Int. J. Food Sci. Technol. 2011, 46, 1245-1252. [CrossRef] 
50. Nabil, Y.; Ouni, Y.; Dabbech, N.; Baccouri, B.; Abdelly, C.; Zarrouk, M. Effect of olive storage period at two different temperatures on oil quality of two Tunisian cultivars of Olea europea, Chemlali and Chétoui. Afr. J. Biotechnol. 2012, 11, 888-895. [CrossRef]

51. Jabeur, H.; Zribi, A.; Abdelhedi, R.; Bouaziz, M. Effect of olive storage conditions on Chemlali olive oil and the effective role of fatty acids alkyl esters in checking olive oil authenticity. Food Chem. 2015, 169, 289-296. [CrossRef]

52. Hbaieb, R.H.; Kotti, F.; Gargouri, M.; Msallem, M.; Vichi, S. Ripening and storage conditions of Chétoui and Arbequina olives: Part I. Effect on olive oils volatiles profile. Food Chem. 2016, 203, 548-558. [CrossRef]

53. Hbaieb, R.H.; Kotti, F.; Cortes-Francisco, N.; Caixach, J.; Gargouri, M.; Msallem, M.; Vichi, S. Ripening and storage conditions of Chétoui and Arbequina olives: Part II. Effect on olive endogenous enzymes and virgin olive oil secoiridoid profile determined by high resolution mass spectrometry. Food Chem. 2016, 210, 631-639. [CrossRef] [PubMed]

54. Oueslati, I.; Zarrouk, M.; Flamini, G. Storage of olives (olea europaea): Effect on the quality parameters and the radical scavenging activity of the total fraction, lipidic and methanolic fractions of the VOO. Acta Hort. 2013, 997, 129-136. [CrossRef]

55. Bozdogan, A.; Eker, T.; Konuskan, D.; Oz, A.T.; Kafkas, E. Effects of the storage of Turkish Gemlik olives under $\mathrm{CO}_{2}$ and $\mathrm{N}_{2}$ on the phenolic compounds and fatty acid compositions of olive oils. J. Food Meas. Charact. 2019, 13, 187-195. [CrossRef]

56. Vali, R.; Ghorbani, S.; Hajnajari, H. Effect of temperature and storage period on olive (Olea europaea cv. Zard) fruit in olive oil quality. J. Food Agric. Environ. 2011, 9, 74-77.

57. Taluri, S.S.; Jafari, S.M.; Bahrami, A. Evaluation of changes in the quality of extracted oil from olive fruits stored under different tempertures and time intervals. Sci. Rep. 2019, 9, 19688. [CrossRef]

58. Bubola, K.B.; Lucić, M.; Novoselić, A.; Krapac, M.; Lukić, I. Olive fruit refrigeration during prolonged storage preserves the quality of virgin olive oil extracted therefrom. Foods 2020, 9, 1445. [CrossRef] [PubMed]

59. García, J.M.; Yousfi, K.; Mateos, R.; Olmo, M.; Cert, A. Reduction of oil bitterness by heating of olive (Olea europaea) fruits. J. Agric. Food Chem. 2001, 49, 4231-4235. [CrossRef]

60. García, J.M.; Yousfi, K.; Oliva, J.; García-Diaz, M.T.; Pérez-Camino, M.C. Hot Water Dipping of Olives (Olea europaea) for Virgen Oil Debittering. J. Agric. Food Chem. 2005, 53, 8248-8252. [CrossRef] [PubMed]

61. García, J.M.; Plasquy, E.; Jiménez-Romero, A.R. Efecto de los tratamientos postcosecha en el contenido fenólico del aceite de olive virgen. Actas Hortic. 2019, 84, 26-30.

62. Yousfi, K.; Cayuela, J.A.; García, J.M. Effect of temperature, modified atmosphere and Ethylene during olive storage on quality and bitterness level of the oil. J. Am. Oil Chem. Soc. 2009, 86, 291-296. [CrossRef]

63. Yousfi, K.; Moyano, M.J.; Martinez, F.; Cayuela, J.A.; García, J.M. Postharvest Heat Treatment for Olive Oil Debittering at the Industrial Scale. J. Am. Oil Soc. 2010, 87, 1053-1061. [CrossRef]

64. Asheri, M.; Sharifani, M.M.; Kiani, G. An examination into the effects of frozen storage of olive fruit on extracted olive oils. Adv. Hort. Sci. 2017, 31, 191-198. [CrossRef]

65. Poerio, A.; Bendini, A.; Cerretani, L.; Bonoli-Carbognin, M.; Lercker, G. Effect of olive fruit freezing on oxidative stability of virgin olive oil. Eur. J. Lipid Sci. Technol. 2008, 110, 368-372. [CrossRef]

66. García-Vico, L.; García-Rodriguez, R.; Sanz, C.; Pérez, A.G. Biochemical aspects of olive freezing-damage: Impact on the phenolic and volatile profiles of virgin olive oil. Food Sci. Technol. 2017, 86, 240-246. [CrossRef]

67. Masella, P.; Guerrini, L.; Angeloni, G.; Spadi, A.; Baldi, F.; Parenti, A. Freezing/storing olives, consequences for extra virgin olive oil quality. Int. J. Refrig. 2019, 106, 24-32. [CrossRef]

68. Nanos, G.D.; Agtsidou, E.; Sfakiotakis, E.M. Temperature and propylene effects on ripening of green and black 'Conservolea' olives. HortScience 2002, 37, 1079-1081. [CrossRef]

69. Nanos, G.D.; Kiritsakis, A.K.; Sfakiotakis, E.M. Preprocessing storage conditions for green 'Conservolea' and 'Chondrolia' table olives. Postharvest Biol. Technol. 2002, 25, 109-115. [CrossRef]

70. Yousfi, K.; Weiland, C.M.; García, J.M. Responses of fruit physiology and virgin oil quality to cold storage of mechanically harvested 'Arbequina' olives cultivated in hedgerow. Grasas Aceites 2013, 64, 572-582. [CrossRef]

71. Guerrini, L.; Corti, F.; Cecchi, L.; Mulinacci, N.; Calamai, L.; Masella, P.; Angeloni, G.; Spadi, A.; Parenti, A. Use of refrigerated cells for olive cooling and short-term storage: Qualitative effects on extra virgin olive oil. Int. J. Refrig. 2021, 127, 59-68. [CrossRef]

72. Ramaswamy, H.S. Post-Harvest Technologies of Fruit E Vegetables; DEStech Publilcations: Lancaster, PA, USA, 2015; ISBN 978-1-932078-27-5.

73. Becker, B.R.; Misra, A.; Fricke, B.A. Bulk refrigeration of fruits and vegetables. Part 1: Theoretical considerations of heat and mass transfer. HVACR Res. 1996, 2, 122-134. [CrossRef]

74. Brosnan, T.; Sun, D.W. Precooling techniques and applications for horticultural products. A review. Int. J. Refrig. 2001, 24, 154-170. [CrossRef]

75. Redding, G.P.; Yang, A.; Shim, Y.M.; Olatunji, J.; East, A. A review of the use and design of produce simulators for horticultural forced-air cooling studies. J. Food Eng. 2016, 190, 80-93. [CrossRef]

76. Mercier, S.; Villeneuve, S.; Mondor, M.; Uysal, I. Time-Temperature Management Along the Food Cold Chain: A review of Recent Developments. Compr. Rev. Food Sci. Food Saf. 2017, 16, 647-667. [CrossRef]

77. Plasquy, E.; Florido, M.C.; Sola-Guirado, R.B.; García-Martos, J.M. Precooling and cold storage of olives (cv Picual) in containers with a capacity of $400 \mathrm{~kg}$. Grasas Aceites 2022, 73, e467. [CrossRef]

78. Plasquy, E.; Sola-Guirado, R.R.; Florido, M.C.; García, J.M.; Blanco Roldán, G. Evaluation of a manual olive fruit harvester for small producers. Res. Agric. Eng. 2019, 65, 105-111. [CrossRef] 
79. Uceda, M.; Frías, L. Épocas de recolección. Evolución del contenido graso del fruto y de la composición y calidad del aceite. In Proceedings of II Seminario Oleícola; IOOC, Ed.; International: Córdoba, Spain, 1975.

80. Folch, J.; Lees, M.; Stanley, G.H.S. A simple method for the isolation and purification of total lipides from animal tissues. J. Biol. Chem. 1957, 226, 497-509. [CrossRef]

81. García, P.; Brenes, M.; Romero, C.; Garrido, A. Respiration and psysicochemical changes in harvested olive fruits. J. Hortic. Sci. 1995, 70, 925-933. [CrossRef]

82. Gutiérrez Rosales, F.; Perdiguero, S.; Gutiérrez, R.; Olias, J.M. Evaluation of the bitter taste in virgin olive oil. J. Am. Oil Chem. Soc. 1992, 69, 394-395. [CrossRef]

83. Koprivnjak, O.; Brkić Bubola, K.; Kosić, U. Sodium chloride compared to talc as processing aid has similar impact on volatile compounds but more favorable on ortho-diphenols in virgin olive oil. Eur. J. Lipid Sci. Technol. 2016, 118, 318-324. [CrossRef]

84. Segovia-Bravo, K.; García-García, P.; Lopéz-Lopéz, A.; Garrido-Fernández, A. Effect of bruising on respiration, superficial colour and phenolic changes in fresh Manzanilla olives (Olea europea pomiformis): Development of treatments to mitigate browning. $J$. Agric. Food Chem. 2011, 59, 5456-5465. [CrossRef] [PubMed]

85. Maxie, E.C.; Catlin, P.B.; Hartman, H.T. Respiration and ripening of olive fruits. Proc. Am. Soc. Hort. Sci. 1960, 75, $275-291$.

86. Fernández-Bolaños, J.; Heredia, A.; Vioque, B.; Castellano, J.M.; Guillén, R. Changes in cell-wall-degrading enzyme activities in stored olives in relation to respiration and ethylene production. Z. Lebensm. Unters. Forsch. A 1997, 204, 293-299. [CrossRef]

87. EC 2568/91. Characteristics of olive and olive pomance oils and their analytical methods. Off. J. 1991, L248, 1-82.

88. USDA [United States Dept of Agriculture]. United States Standards for Grades of Olive Oil and Olive-Pomace Oil; United States Department of Agriculture: Washington, DC, USA, 2010. Available online: https://www.ams.usda.gov/sites/default/files/ media/Olive_Oil_and_Olive-Pomace_Oil_Standard\%5B1\%5D.pdf (accessed on 25 June 2021).

89. Ben-Yahia, L.; Baccouri, B.; Ouni, Y.; Hamdi, S. Quality, stability and radical scavenging activity of olive oils after Chétoui olives (Olea europaea L.) storage under modified atmospheres. Food Sci. Technol. Int. 2012, 18, 353-365. [CrossRef]

90. Beltrán, G.; Aguilera, M.P.; Del Rio, C.; Sanchez, S.; Martínez, L. Influence of fruit ripening process on the natural antioxidant content of Hojiblanca virgin olive oils. Food Chem. 2005, 89, 207-215. [CrossRef]

91. Oueslati, I.; Krichene, D.; Manaï, H.; Taamalli, W.; Zarrouk, M.; Flamini, G. Monitoring the volatile and hydrophilic bioactive compounds status of fresh and oxidized Chemlali virgin olive oils ovr olive storage times. Food Res. Int. 2018, 112, 425-433. [CrossRef] [PubMed]

92. Morales-Silero, A. Influencia de la recolección en la composición fenólica. Actas Hortic. 2019, 84, 22-25.

93. Pérez, A.P.; Sanz, C. Composición fenólico del aceite de oliva: Compuestos y enzimas implicados. Actas Hortic. 2019, 84, 7-9.

94. Tsimidou, M.Z. Analytical Methodologies: Phenolic compounds related to olive oil taste issues. In Handbook of Olive Oil, Analysis and Properties, 2nd ed.; Aparicio, R., Harwood, J., Eds.; Springer: New York, NY, USA, 2013; pp. 311-334.

95. Hbaieb, R.H.; Kotti, F.; García-Rodriguez, R.; Gargouri, M.; Sanz, C.; Pérez, A.G. Monitoring endogenous enzymes during olive fruit ripening and storage: Correlation with virgin olive oil phenolic profiles. Food Chem. 2015, 174, 240-247. [CrossRef] [PubMed]

96. Beltrán, G.; Jiménez, A.; del Rio, C.; Sánchez, S.; Martínez, L.; Uceda, M.; Aguilera, M.P. Variability of vitamine E in virgin olive oil by agronomical and genetic factors. J. Food Compost. Anal. 2010, 23, 633-639. [CrossRef]

97. Bendini, A.; Valli, E.; Cerretani, L.; Chiavaro, E.; Lercker, G. Study on the effects of heating of virgin olive oil blended with mildly deodorized olive oil: Focus on the hydrolytic and oxidative state. J. Agric. Food. Chem. 2009, 57, 10055-10062. [CrossRef] [PubMed]

98. Gómez-Coca, R.B.; Cruz-Hidalgo, R.; Fernades, G.D.; Pérez-Camino, M.C.; Moreda, W. Analysis of methanol and ethanol in virgin olive oil. MethodsX 2014, 1, 207-211. [CrossRef]

99. García-Vico, L.; Belaj, A.; León, L.; de la Rosa, R.; Sanz, C.; Pérez, A.G. A survey of ethanol content in virgin olive oil. Food Control 2018, 91, 248-253. [CrossRef]

100. EC 1348/2013. Regulation No 2568/91/EEC on the characteristics of olive oil and olive-residue oil and on the relevant methods of analysis. Off. J. 2013, L338, 31-67.

101. Beltrán, G.; Sánchez, R.; Sánchez-Ortiz, A.; Aguilera, M.P.; Bejaoui, M.A.; Jiménez, A. How 'ground-picked' olive fruits affect virgin olive oil ethanol content, ethyl esters and quality. J. Sci. Food Agric. 2016, 96, 3801-3806. [CrossRef] [PubMed]

102. Lorite, I.J.; Gabaldón-Leal, C.; Ruiz-Ramos, M.; Belaj, A.; de la Rosa, R.; León, L.; Santos, C. Evaluation of olive response and adaptation strategies to climate change under semi-arid conditions. Agric. Water Manag. 2018, 204, 247-261. [CrossRef]

103. Benlloch-González, M.; Sánchez-Lucas, R.; Bejaoui, M.A.; Benlloch, M.; Fernández-Escobar, R. Global warming effects on yield and fruit maturation of olive trees growing under field conditions. Sci. Hortic. 2019, 249, 162-167. [CrossRef]

104. Rallo, L.; Díez, C.M.; Morales-Silero, A.; Miho, H.; Priego-Capote, F.; Rallo, P. Quality of olives: A focus on agricultural preharvest factors. Sci. Hortic. 2018, 233, 491-509. [CrossRef]

105. Rébufa, C.; Pinatel, C.; Artaud, J.; Girard, F. A comparative study of the main international extra virgin olive oil competitions: Their impact on producers and consumers. Trends Food Sci. Technol. 2021, 107, 445-454. [CrossRef]

106. Di Serio, M.G.; Giansante, L.; Di Loreto, G.; Faberi, A.; Ricchetti, L.; Di Giacinto, L. Ethyl esters versus fermentative organoleptic defects in virgin olive oil. Food Chem. 2017, 219, 33-39. [CrossRef]

107. Ministerio de Agricultura, Pesca y Alimentación. Real decreto 41/2021. BOE 2021, 23, 7955-7977.

108. Inarejos-García, A.M.; Gómez-Rico, A.; Salvador, M.D.; Fregapane, G. Influence of malaxation condition on virgin olive oil yield, overall quality and composition. Eur. Food Res. Technol. 2009, 228, 671-677. [CrossRef] 
109. Peri, C. Quality Excellence in Extra Virgin Olive Oils. In Olive Oil Sensory Science; Monteleone, E., Langstaff, S., Eds.; John Wiley: Chichester, UK, 2014; pp. 3-32.

110. Caponio, F.; Gomes, T.; Summo, C.; Pasqualone, A. Influence of the type of olive-crusher used on the quality of extra virgin olive oils. Eur. J. Lipid Sci. Technol. 2003, 105, 201-206. [CrossRef]

111. Al-Widyan, M.I.; Rababah, T.M.; Mayyas, A.; Al-Shbool, M.; Yang, W. Geometrical, thermal and mechanical properties of olive fruits. J. Food Process. Eng. 2010, 33, 257-271. [CrossRef]

112. Cuesta, F.; Alvarez, M. Mathematical modeling for heat conduction in stone fruits. Int. J. Refrig. 2017, 80, 120-129. [CrossRef]

113. Plasquy, E.; García, J.M.; Florido, M.C.; Sola-Guirado, R.R. Estimation of the cooling rate of six olive cultivars using thermal imaging. Agriculture 2021, 11, 164. [CrossRef]

114. Çengel, Y.N.; Ghajar, A.J. Heat and Mass Transfer Fundamentals \& Applications, 5th ed.; McGraw-Hill Education: New York, NY, USA, 2015.

115. Wang, G.; Zhang, X. Evalutation and optimization of air-based pre-cooling for higher postharvest quality: Literature review and interdisciplinary perspective. Food Qual. Saf. 2020, 4, 59-68. [CrossRef]

116. Ben-Shalom, N.; Harel, E.; Mayer, A.M. Enzymatic browning in green olives and its prevention. J. Sci. Food Agric. 1978, 29, 398-402. [CrossRef]

117. Rejano-Navarro, L.; Sánchez-Gomez, A.H.; Vega Macías, V. Nuevas tendencias en el tratamiento alcalino "cocido" de las aceitunas verdes aderezadas al estilo español o sevillano. Grasas Aceites 2008, 59, 197-204.

118. Vichi, S.; Boynuegri, P.; Caixach, J.; Romero, A. Quality losses in virgin olive oil due to washing and short-term storage before olive milling. Eur. J. Lipid Sci. Technol. 2015, 177, 2015-2022. [CrossRef]

119. Bower, J.H.; Jobling, J.J.; Patterson, B.D.; Ryan, D.J. A method for measuring the respiration rate and respiratory quotient of detached plant tissues. Postharvest Biol. Technol. 1998, 13, 263-270. [CrossRef]

120. Fonseca, S.; Oliveira, F.; Brecht, J.K. Modelling respiration rate of fresh fruits and vegetables for modified atmosphere packages: A review. J. Food Eng. 2002, 52, 99-119. [CrossRef]

121. Caleb, O.J.; Mahajan, P.V.; Opara, U.L.; Witthuhn, C.R. Modelling the respiration rates of pomegranate fruit and arils. Postharvest Biol. Technol. 2012, 64, 49-54. [CrossRef]

122. Iqbal, T.; Rodrigues, F.A.S.; Mahajan, P.V.; Kerry, J.P. Effect of time, temperature, and slicing on respiration rate of mushrooms. J. Food Sci. 2009, 74, 6. [CrossRef]

123. Waghmare, R.B.; Mahajan, P.V.; Annapure, U.S. Modelling the effect of time and temperature on respiration rate of selected fresh-cut produce. Postharvest Biol. Technol. 2013, 80, 25-30. [CrossRef]

124. Elansari, A.M. Design aspects in the precooling process of fresh produce. Fresh Prod. 2009, 3, 49-57.

125. Elansari, A.M.; Fenton, D.L.; Callahan, C.W. Postharvest Technology of Perishable Horticultural Commodities; Yahia, E.M., Ed.; Woodhead Publishing: Duxford, UK, 2019; pp. 161-207. [CrossRef]

126. Duan, Y.; Wang, G.; Fawole, A.; Verboven, P.; Zhang, X.; Wu, D.; Opara, U.L.; Nicolaï, B.; Chen, K. Postharvest precooling of fruit and vegetables: A review. Trends Food Sci. Technol. 2020, 100, 278-291. [CrossRef]

127. Wang, S.; Tang, J.; Cavalieri, R.P. Modeling fruit internal heating rates for hot air and hot water treatments. Postharvest Biol. Technol. 2001, 22, 257-270. [CrossRef]

128. Kitinoja, L.; Thompson, J.F. Pre-cooling systems for small-scale producers. Stewart Postharvest Rev. 2010, 2, 2-14. [CrossRef]

129. Veneziani, G.; Esposto, S.; Taticchi, A.; Urbani, S.; Selvaggini, R.; Di Maio, I.; Sordini, B.; Servili, M. Cooling treatment of olive paste during the oil processing: Impact on the yield and extra virgin olive oil quality. Food Chem. 2017, 221, 107-113. [CrossRef]

130. Mercacei. El lado oscuro: Tolvas y aceite de oliva virgen extra. Mercacei 2020. Available online: https://www.mercacei.com/ imprimir-noticia.asp?noti=53283 (accessed on 25 June 2021).

131. Olimerca. Túnel Criogénico Para Mejorar la Calidad del Aceite Virgen Extra. Olimerca, 03/11/2020. Available online: https: / / www.olimerca.com/noticiadet/tunel-criogenico-para-mejorar-la-calidad-del-aceite-virgen-extra/f75ce756489ab60d3 21ea7120bffa889 (accessed on 25 June 2021).

132. Beltrán, G.; Hueso, A.; Bejaoui, M.A.; Gila, A.M.; Costales, R.; Sánchez-Ortiz, A.; Aguilera, M.P.; Jiménez, A. How olive washing and storage affect fruit ethanol and virgin olive oil ethanol, ethyl esters and composition. J. Sci. Food Agric. 2020. epub ahead of print online. [CrossRef]

133. Dourou, A.M.; Brizzolara, S.; Famiani, F.; Tonutti, P. Effects of pre-processing low temperature conditioning of olives on volatile organic compounds (VOC) profiles of fruit paste and oil. Acta Hortic. 2019, 1256, 53-57. [CrossRef]

134. Amirante, P.; Clodoveo, M.L.; Dugo, G.; Leone, A.; Tamborrino, A. Advance technology in vigin olive oil production from traditional and de-stoned pastes: Influence of the introduction of a heat exchanger on oil quality. Food Chem. 2006, 98, 797-805. [CrossRef]

135. Clodoveo, M.L. Malaxation: Influence on virgin olive oil quality. Past, present and future. An overview. Trends Food Sci. Technol. 2012, 25, 13-23. [CrossRef]

136. Esposto, S.; Veneziani, G.; Taticchi, A.; Selvaggini, R.; Urbani, S.; Di Maio, I.; Sordini, B.; Minnocci, A.; Sebastiani, L.; Servili, M. Flash Thermal Conditiong of Olive Pastes during the Olive Oil Mechanical Extraction Process: Impact on the Structural Modifications of Pastes and Oil Quality. J. Agric. Food Chem. 2013, 61, 4953-4960. [CrossRef]

137. Fiori, F.; Di Lecce, G.; Boselli, E.; Pieralisi, G.; Frega, N.G. Effects of olive paste fast preheating on the quality of extra virgin olive oil during storage. LWT-Food Sci. Technol. 2014, 58, 511-518. [CrossRef] 
138. Leone, A.; Esposto, S.; Tamborrino, A.; Romaniello, R.; Taticchi, A.; Urbani, S.; Servilli, M. Using a tubular heat exchanger to improve the conditioning process of the olive paste: Evaluation of yield and olive oil quality. Eur. J. Lipid Technol. 2016, 118, 308-317. [CrossRef]

139. Bejaoui, M.A.; Sánchez-Ortiz, A.; Sánchez, S.; Jiménez, A.; Beltrán, G. The high-power ultrasound frequency: Effect on the virgin olive oil yield and quality. J. Food Eng. 2017, 207, 10-17. [CrossRef]

140. Cecchi, L.; Bellumori, M.; Corbo, F.; Milani, G.; Clodoveo, M.L.; Mulinacci, N. Implementation of the Sono-Heat-Exchanger in the Extra Virgen Olivo Oil Extraction Process: End-User validation and Analytical Evaluation. Molecules 2019, 24, 2379. [CrossRef]

141. Tamborrino, A.; Romaniello, R.; Caponio, F.; Squeo, G.; Leone, A. Combined industrial olive oil extraction plant using ultrasounds, microwave, and heat exchange: Impact on olive oil quality and yield. J. Food Eng. 2019, 245, 124-130. [CrossRef]

142. Clodoveo, M.L. Industrial Ultrasound Applications in the Extra-Virgin Olive Extraction Proces: History, Approaches, and Key Questions. Foods 2019, 8, 121. [CrossRef]

143. Stillitano, T.; Falcone, G.; De Luca, A.I.; Piga, A.; Conte, P.; Strano, A.; Gulisano, G. A life cycle perspective to assess the environ-mental and economic impacts of innovative technologies in extra virgin olive oil extraction. Foods 2019, 8, 209. [CrossRef]

144. Plasquy, E.; García, J.M.; Florido, M.C.; Sola-Guirado, R.R.; García-Martín, J.F. Adjustment of olive fruit temperature before grinding for olive oil extraction; Experimental study and pilot plant trials. Processes 2021, 9, 586. [CrossRef]

145. Luaces, P.; Pérez, A.G.; Sanz, C. Effect of the blanching process and olive fruit temperature at milling on the biosynthesis of olive oil aroma. Eur. Food Res. Technol. 2006, 224, 11-17. [CrossRef]

146. Cruz, S.; Yousfi, K.; Oliva, J.; García, J.M. Heat Treatment Improves Olive Oil Extraction. J. Am. Oil Soc. 2007, 84, 1063-1068. [CrossRef] 